\title{
Cortical activities associated with voluntary movements and involuntary movements.
}

\author{
$\operatorname{AUTHOR}(S)$ :
}

Shibasaki, Hiroshi

\section{CITATION:}

Shibasaki, Hiroshi. Cortical activities associated with voluntary movements and involuntary movements.. Clinical neurophysiology 2012, 123(2): 229-243

\section{ISSUE DATE:}

2012-02

URL:

http://hdl.handle.net/2433/153025

\section{RIGHT:}

(C) 2011 International Federation of Clinical Neurophysiology. Published by Elsevier Ireland Ltd.; This is not the published version. Please cite only the published version.; この 論文は出版社版でありません。引用の際には出版社版をご確認ご利用ください。 
Review

\title{
Cortical Activities Associated with Voluntary Movements and Involuntary Movements
}

\author{
Hiroshi Shibasaki \\ Emeritus Professor, Kyoto University Graduate School of Medicine \\ Human Brain Research Center, Kyoto University Graduate School of \\ Medicine, Shogoin, Sakyo, Kyoto, 606-8507 Japan
}

Keywords: voluntary movement; involuntary movement;

Bereitschaftspotential; jerk-locked back averaging; neuroimaging; negative motor phenomena; motor imagery

Based on Tokizane Lecture presented in a joint session of the $29^{\text {th }}$ International Congress of Clinical Neurophysiology and the $40^{\text {th }}$ Annual Congress of the Japanese Society of Clinical Neurophysiology on November 1, 2010 in Kobe. 


\section{Highlights}

1. Recent advance in clinical neurophysiology and functional neuroimaging contributed greatly to the understanding of the control mechanism of voluntary movements and pathophysiology of involuntary movements.

2. The sensorimotor cortex, the origin of the final common pathway for voluntary movement, is involved in generation of involuntary movements, especially cortical myoclonus, tremor and focal dystonia.

3. Negative or inhibitory motor phenomena are important for both voluntary and involuntary movements.
Abstract
Recent advance in non-invasive techniques including electrophysiology and functional neuroimaging has enabled investigation of control mechanism of voluntary movements and pathophysiology of involuntary movements in human. Epicortical recording with subdural electrodes in epilepsy patients complemented the findings obtained by the non-invasive techniques. Before self-initiated simple movement, activation occurs first in the pre-supplementary motor area (pre-SMA) and SMA proper bilaterally with some somatotopic organization, and the lateral premotor area (PMA) and primary motor cortex (M1) mainly contralateral to the movement with precise somatotopic organization. Functional connectivity among cortical areas has been disclosed by cortico-cortical coherence, cortico-cortical evoked potential, and functional MRI. Cortical activities associated with involuntary movements have been studied by jerk-locked back averaging and cortico-muscular coherence. Application of transcranial magnetic stimulation helped clarifying the state of excitability and inhibition in M1. Sensorimotor cortex (S1-M1) was shown to play an important role in generation of cortical myoclonus, essential tremor, Parkinson tremor and focal dystonia. Cortical myoclonus is actively driven by S1-M1 while essential tremor and Parkinson tremor are mediated by S1-M1. 'Negative motor areas' at PMA and pre-SMA and 'inhibitory motor areas' at peri-rolandic cortex might be involved in the control of voluntary movement and generation of negative involuntary movements, respectively. 
Contents

1. Introduction

page 5

2. Cortical activities associated with self-initiated simple movements 5

a. Movement-related cortical potentials 6

b. Movement-related power change of cortical oscillations $\quad 9$

$\begin{array}{ll}\text { c. Cortico-muscular coherence } & 10\end{array}$

d. Complex sequence of muscle contraction compared with simple movement 11

3. Cortical activities associated with movements used for daily lives 13

a. Cortical activities associated with gait 13

$\begin{array}{ll}\text { b. Cortical activities associated with swallowing } & 14\end{array}$

c. Cortical activities associated with praxis movements $\quad 15$

4. Mechanism of voluntary motor inhibition 16

a. Negative motor area vs. inhibitory motor area 16

$\begin{array}{ll}\text { b. Voluntary motor inhibition } & 17\end{array}$

5. Cortical activities associated with motor imagination 18

6. Will to move and significance of BP 19

7. Movement-related cortical potentials in pathological conditions 21

8. Jerk-locked back averaging 21

9. Cortical activities associated with involuntary movements 22

a. Cortical myoclonus $\quad 22$

b. Tremor 24

c. Focal dystonia 26

d. Asterixis in thalamic lesion $\quad 27$

$\begin{array}{ll}\text { 10.Integration } & 27\end{array}$ 
Abbreviation

BP: Bereitschaftspotential

CNV: contingent negative variation

ECoG: electrocorticogram

EEG: electroencephalography $(\mathrm{m})$

EMG: electromyography $(\mathrm{m})$

ERD: event-related desynchronization

ERS: event-related synchronization

fMRI: functional magnetic resonance imaging

IPL: inferior parietal lobule

LFP: local field potential

M1: primary motor cortex,

MEG: magnetoencephalography $(\mathrm{m})$

MEP: motor evoked potential

MP: motor potential

MRCP: movement-related cortical potential

NS': Negative Slope

PET: positron emission tomography

PMA: premotor area

rCBF: regional cerebral blood flow

S1: primary somatosensory cortex

S1-M1: sensorimotor cortex

SEP: somatosensory evoked potential

SMA: supplementary motor area

SPECT: single photon emission computed tomography

STN: subthalamic nucleus

Vim: nucleus ventralis intermedius

Vop: nucleus ventralis oralis posterior

1. Introduction 
This review article is based on Tokizane Lecture that the author presented in a joint session of the $29^{\text {th }}$ International Congress of Clinical Neurophysiology and the $40^{\text {th }}$ Annual Congress of the Japanese Society of Clinical Neurophysiology on November 1, 2010 in Kobe. Professor Toshihiko Tokizane (1909-1973), Director of Brain Research Institute, University of Tokyo School of Medicine, founded the Japanese Society of Electromyography (EMG) in 1952. In 1971 the EMG Society joined the Japanese Society of Electroencephalography (EEG) to form a single society, Japanese Society of EEG and EMG, for which Professor Tokizane served as the first President. In 2000 the name of the Society was changed to the Japanese Society of Clinical Neurophysiology. Professor Tokizane's Textbook of EMG written in Japanese was a gold standard of clinical EMG in Japan at that time.

Movements are divided into voluntary movement, automatic movement and involuntary movement. Voluntary movement is usually self-initiated but may also be induced in response to cue signal or stimulus. Automatic movement is employed in daily activities and includes blinks, spontaneous eye movements, chewing, swallowing, yawning, respiration and walking. These automatic movements can be either totally self-initiated or is often executed without conscious will to move. Involuntary movements are mostly pathological with exception of physiologic tremor and nocturnal myoclonus. Recent advance in electrophysiological techniques and functional neuroimaging contributed greatly to the increased understanding of the central control mechanism of voluntary movement and of pathophysiology underlying generation of various involuntary movements. This article reviews cortical activities revealed by techniques of different principles in association with voluntary and involuntary movements in human, and integrates the interrelationship between voluntary and involuntary movements including negative motor phenomena.

\section{Cortical activities associated with self-initiated simple movements}

Most physiological studies on voluntary movements have employed self-initiated contraction of a single muscle or a group of muscles producing a simple movement. It was Bates in 1951 who first tried to record cortical activities preceding voluntary muscle contraction by EEG. Since no back averaging program was available at that time, he recorded EEG and the 
surface EMG simultaneously while the subject repeated self-paced hand grips, and superimposed photographs of each individual EEG time-locked to the EMG. By this method of photographic superimposition, he detected small EEG potentials after the onset of voluntary movement, but no potential was recognized before the movement (Bates, 1951). He further produced brief twitch of the wrist by electric shock of the median nerve and trained the subject to produce a voluntary movement identical to the evoked movement, and observed similar EEG potentials immediately after the voluntary movement and the passive movement (Bates, 1951).

\section{a. Movement-related cortical potentials}

It was Kornhuber and Deecke in 1964 that first succeeded in demonstrating EEG activities preceding self-paced muscle contraction (Kornhuber and Deecke, 1964, 1965). In their original method, they stored the simultaneously recorded EEG and EMG associated with self-paced muscle contraction in a magnetic tape, and after completing the recording session they reproduced the tape chronologically backward and averaged EEG time-locked to the onset of EMG so that pre-movement activities could be detected. By this technique they identified four components of EEG, three before and one after the EMG onset.

The slowly rising surface-negative potential starting $1-1.5 \mathrm{~s}$ before the movement onset was named Bereitschaftspotential (BP) or readiness potential by Kornhuber and Deecke (1965). BP was composed of an early slope maximal at the central midline and a later steeper slope over the central area larger contralateral than ipsilateral to the moved finger. BP was followed by a positive peak called pre-motion positivity, a small negative peak called motor potential (MP) and a post-motion positive complex named Reafferente Potentiale. MP was localized to the central area contralateral to the hand movement and was considered to represent an activity of the pyramidal tract cells in the primary motor cortex (M1). Subsequently they made a series of studies on this subject including the use of magnetoencephalography (MEG), and emphasized an important role of supplementary motor area (SMA) in the generation of BP (Kornhuber and Deecke, 1965; Deecke et al., 1969, 1982, 1983, 1987; Deecke and Kornhuber, 1978, 2003).

In 1980 the author's group recorded the movement-related cortical 
potential (MRCP) by taking advantage of a large computer available for that time at the Institute of Neurology, Queen Square. As the result, at least eight components, four each before and after the movement onset, were identified based on different distribution of each component over the scalp and different timing with respect to the movement onset (Shibasaki et al., 1980a, 1981; Barrett et al., 1985, 1986). The pre-movement components were BP and Negative Slope (NS') corresponding to early BP and late BP, respectively, P-50 corresponding to the pre-motion positivity, and N-10 corresponding to MP (Shibasaki et al., 1980a). The post-movement components were $\mathrm{N}+50, \mathrm{P}+90, \mathrm{~N}+160$, and $\mathrm{P}+300$ corresponding to the Reafferente Potentiale (Shibasaki et al., 1980a; see Shibasaki and Hallett, 2006 for comparison of terminology). The four post-movement components were similar to four components identified after the onset of passive finger movement in terms of spatial distribution and timing with respect to the movement onset, supporting that those potentials represent kinesthetic feedback (Shibasaki et al., 1980b).

Since voluntary movements are considered to be produced by concurrent and/or successive activation of different areas of motor cortices with close proximity each other in time and space, different components of EEG recorded from the head surface in association with the movement are expected to overlap each other as the result of volume conduction of each component. In this regard, application of MEG, owing to its higher spatial resolution compared to EEG, complemented the information as to the generator mechanism of MRCP. Based on the MEG data, Deecke and his group emphasized an important role of SMA in generation of BP (Deecke et al., 1982; Lang et al., 1991; Erdler et al., 2000; Deecke and Kornhuber, 2003). MEG has a disadvantage of inability to detect a component generated from a radially oriented dipole, e.g. potentials originating from the crown of the precentral or postcentral gyrus (Nagamine et al., 1996; Shibasaki et al., 2007). However, as it is the anterior and posterior banks of the central sulcus that are activated immediately before and after the movement onset thus producing tangentially oriented dipoles, MEG was especially useful for identifying the generator sources of those potentials such as MP (N-10) and $\mathrm{N}+50$ (Gerloff et al., 1998). The similar sequence of activation within different areas of motor cortices was demonstrated also by event-related functional magnetic resonance imaging (fMRI) (Cunnington et al., 2002, 
2003). For the study of central control mechanism of voluntary movement, the functional neuroimaging techniques based on hemodynamic principle and the electrophysiological techniques complemented each other owing to its high spatial and temporal resolution, respectively (Shibasaki, 2008).

In order to clarify the generator mechanism of MRCP more precisely, the author's group collaborated with Luders and his group of Cleveland by taking advantage of the opportunities to directly record cortical potentials from subdurally placed electrodes in patients with medically intractable partial epilepsy as a part of pre-surgical evaluation (Luders et al., 1992). By contrast with scalp recording of EEG, epicortical recording with subdural electrodes has much higher spatial resolution because it is not influenced by volume conduction, although the cortical area covered by the subdural electrodes is limited and the cortical sulci are not usually covered by the electrodes. As the result of epicortical recording in patients who had epileptogenic foci at or near the sensorimotor cortex (S1-M1) or SMA, it was found that early BP starts first in the SMA including pre-SMA and SMA proper and then shortly thereafter occurs in the lateral premotor area (PMA) bilaterally, and about $400 \mathrm{~ms}$ prior to the movement onset the late BP (NS') starts in M1 and the lateral PMA predominantly contralateral to the movement (Neshige et al., 1988; Ikeda et al., 1992, 1996a; Ohara et al., 2000a; Yazawa et al., 2000).

Within the SMA proper, there is a somatotopic organization with the face area located rostral and the leg area caudal, although not as discrete as in $\mathrm{M} 1$, and early BP is bilaterally generated from the localized area of the SMA proper following its somatotopic organization (Ikeda et al., 1992; Ohara et al., 2000a; Yamamoto et al., 2004). In contrast, late BP is well localized to a part of M1 and a part of the lateral PMA clearly following the somatotopic organization. In M1, the late BP culminates in MP (N-10) just before the movement onset. MP (N-10) is generated from a small area of M1 precisely corresponding to the somatotopic distribution. The generator sources of post-movement components have not been clearly identified, partly because it is difficult to correlate the scalp-recorded peaks to the peaks identified by epicortical recording (Neshige et al., 1988).

In regard to eye movements, recording of MRCP with subdural electrodes in patients as a part of pre-surgical evaluation revealed BP preceding self-initiated horizontal saccade localized at $1-2 \mathrm{~cm}$ rostral to the hand, arm 
or face area of M1, which was identified as the frontal eye field by stimulation study, and at the rostral part of SMA proper corresponding to the supplementary eye field (Yamamoto et al., 2004).

\section{b. Movement-related power change of cortical oscillations}

In addition to the analysis of field potentials described in Section $2 \mathrm{a}$, cortical activities can also be studied by analyzing the power change of EEG oscillations in the frequency domain. Power decrease in $\alpha$ or $b$ bands time-locked to an event or a task, event-related desynchronization (ERD), is considered to represent increased activation of the corresponding cortical area while power increase, event-related synchronization (ERS), is associated with return to the resting condition or even decreased activation (Pfurtscheller and Aranibar, 1977; Pfurtscheller and Neuper, 2003; Pfurtscheller, 2006).

The movement-related decrease of $\alpha$ and $B$ bands shows a different spatio-temporal pattern from that of BP (Nagamine et al., 1996). Babiloni et al. (1999) reported that, for the right-hand movement in right-handed subjects, the ERD starts over the left hemisphere and then spreads bilaterally toward the movement onset. As discussed in Section 2a, the early BP is maximal at the midline and symmetrically distributed over the left and right hemispheres while the late $\mathrm{BP}$ is larger over the contralateral hemisphere regardless of the side of hand movement. Bai et al. (2005) showed evolutions of ERD which is different depending on the side of hand movement. When right-handed subjects moved the right-hand, ERD of $b$ band started over the left hemisphere and became more bilateral toward and during the movement. For the left-hand movement of right-handed subjects, the ERD started bilaterally and remained bilateral throughout. This finding is in conformity with the clinical concept of sympathetic apraxia and callosal apraxia seen in the left hand of the right-handed patients with the lesion of the left PMA and corpus callosum, respectively.

ERD data obtained from subdural electrodes in epilepsy patients revealed that ERD for $B$ band starts in the SMA bilaterally as early as $4 \mathrm{~s}$ before brisk finger movement, and then the precentral gyrus (the crown corresponding to area 6 ) shows ERD for $\alpha$ and $B$ bands, again bilaterally with contralateral predominance (Ohara et al., 2000a). In strong contrast, the post-motion event-related power increase (ERS) for high frequency band is seen 
exclusively in the contralateral postcentral gyrus (Ohara et al., 2000a). By calculating movement-related change in the correlation of rhythmic electrocorticographic (ECoG) oscillations between the mesial and lateral aspects of frontal lobe in epilepsy patients, Ohara et al. (2001) showed increased coherence (cortico-cortical coherence) in the frequency range of 10-20 Hz between the somatotopically corresponding areas of SMA proper and M1, starting $0.9 \mathrm{~s}$ before the movement onset. The functional connectivity between these two areas was substantiated by cortico-cortical evoked potentials in epilepsy patients (Matsumoto et al., 2007).

Cortico-cortical evoked potential is a new method to demonstrate direct or indirect functional connectivity between different cortical areas by electrically stimulating subdural electrodes placed on a cortical area and recording evoked potential from other cortical areas (Matsumoto et al., 2004).

\section{c. Cortico-muscular coherence}

Relationship between voluntary muscle contraction and EEG or MEG activity can also be studied by calculating correlation of certain frequency band between EEG/MEG and EMG during sustained muscle contraction (cortico-muscular coherence) (Conway et al., 1995; Salenius et al., 1997; Brown et al., 1998; Halliday et al., 1998; Mima and Hallett, 1999). Ohara et al. (2000b) analyzed the coherence between electrocorticogram (ECoG) recorded from lateral and mesial peri-rolandic cortex and EMGs of the contralateral wrist extensor muscle during continuous isometric contraction in patients with medically intractable partial epilepsy. They observed a significant cortico-muscular coherence at $15 \mathrm{~Hz}$ on average in the somatotopically corresponding area of M1 and SMA proper, and at $12 \mathrm{~Hz}$ on average in the somatotopically corresponding area of the primary somatosensory cortex (S1). Time lag between the cortical activity and EMG can be calculated by cross-correlogram, but the time lag estimated by this method is much shorter than expected from other methods such as direct cortical stimulation or transcranial magnetic stimulation (TMS) (Brown et al., 1998; Ohara et al., 2000b). Thus, the cortico-muscular coherence provides relatively precise spatial information in the frequency domain, but rather poor information in the time domain. 
d. Complex sequence of muscle contraction compared with simple movement

In contrast to the simple movement as discussed in Section $2 \mathrm{a}$ and $2 \mathrm{~b}$, complex movement involving successive contraction of different muscles is expected to be associated with activation of a more complex set of motor cortices. A number of functional neuroimaging studies have been performed to elucidate the effect of 'complexity' of voluntary movement on the cerebral activity, by using gamma-camera (Orgogozo and Larsen, 1979; Roland et al., 1980) and positron emission tomography (PET) (Deiber et al., 1991; Grafton et al., 1992; Sadato et al., 1996), both measuring the regional cerebral blood flow (rCBF) activation. All those studies have shown an important role of SMA in the complex movement. The complex movement adopted in the PET study by the authors' group was composed of touching the right thumb against the index finger twice, middle finger once, ring finger three times and the little finger twice in this order and then repeating in the reversed order, while the simple movement was a repetition of touching the right thumb against the tips of all other finger of the same hand (Shibasaki et al., 1993). In that study, the increased activation by the complex movement compared with the simple movement was demonstrated not only in SMA but also in bilateral S1-M1. Sadato et al. (1996) studied the effect of different complexity on auditory cued sequential finger movements of the right hand by PET, and found increased activation in bilateral S1-M1, left ventral PMA, posterior SMA, right superior part of cerebellum and the left putamen. Functional magnetic resonance imaging (fMRI) study by Rao et al. (1993) showed activation in the contralateral M1 during simple finger movement whereas in SMA and PMA in addition to the contralateral S1-M1 during complex movements.

Functional neuroimaging studies provide spatial information of high resolution but relatively poor temporal information (Shibasaki, 2008). Therefore, studies of BP associated with simple and complex movements are expected to provide superior time information as to when the complexity of movements is reflected in the cortical activity. Benecke et al. (1985) employed sequential or simultaneous performance of isotonic elbow flexion and isometric fist clenching as a complex task and either isotonic elbow flexion alone or isometric fist clenching alone as a simple task, and found larger BP before the complex task. Simonetta et al. (1991) employed a sequential task of pulling down a toggle switch, then immediately moving 
the hand and forearm to turn on and off a button, and found an earlier onset and larger amplitude of BP in the sequential task.

In order to adjust the number of contracting muscles and the duration of movement in the simple and complex conditions, Kitamura et al. (1993b) compared sequential movement consisting of middle finger extension followed by index finger extension with simultaneous extension of the middle and index fingers, and found larger late BP (NS') in the sequential movement as compared with the simultaneous movement. Since the amplitude difference between the sequential and simultaneous movements was found over the midline vertex as well as bilateral central regions, it was postulated that not only SMA but also bilateral S1-M1 might play an important role in the preparation of complex movement (Kitamura et al., 1993b). Taken together with the above-described neuroimaging data, it is postulated that not only SMA but also S1-M1 plays an important role in the preparation and execution of complex movements. Furthermore, although it depends on how to define 'complexity' of the movement, at least as far as the sequential against simultaneous movements are concerned, the effect of complexity is reflected in the later pre-movement period (within at least $1 \mathrm{~s}$ before the movement onset) (Kitamura et al., 1993b).

Greater activation of ipsilateral S1-M1 with complex movement of unilateral hand compared with simple movement is important in relation to the interpretation of the results of the study of stroke recovery. Regardless of whether electrophysiological study or functional neuroimaging is employed, when S1-M1 is bilaterally activated with unilateral simple movement of the affected hand in patients during stroke recovery, it might be resulting from subjective difficulty or relatively greater complexity of the motor task for the patients, and it may not necessarily indicate participation of the ipsilateral (unimpaired) hemisphere in the stroke recovery.

Discreteness of movement is another factor influencing BP. Kitamura et al. (1993a) compared isolated extension of the middle finger with simultaneous extension of the middle and index fingers, and found larger amplitude of late BP in the isolated movement of the middle finger as compared with the simultaneous movement of the two fingers in spite of the fact that the number of contracting muscles was larger in the simultaneous movement than in the isolated movement. Since the above difference was not found in early BP and since the amplitude difference of late BP was 
found only over the central region contralateral to the movement, the above finding supported the notion that M1 plays an important role in discrete or fractionated finger movement. This is in conformity with the clinical observation that impairment of discrete finger movement is an earliest sign of M1 lesion.

3. Cortical activities associated with movements used for daily lives

Movements commonly used for daily lives such as blinks, spontaneous eye movements, chewing, swallowing, yawning, respiration and walking can be executed almost automatically without conscious intention, and thus the associated cortical activities are expected to vary depending on how much the conscious intention to move is involved during preparation and execution of the movement. Therefore, experimental paradigms for investigating these semi-automatic movements have been limited to the conscious condition.

\section{a. Cortical activities associated with gait}

Vidailhet et al. (1993) recorded MRCP in normal subjects and patients with mild to moderate Parkinson's disease before stepping movement while standing and compared with simple foot movement while sitting. They found a larger BP before the stepping movement as compared with simple foot movement in normal subjects, but the difference between the stepping and the simple foot movement was lacking in Parkinson patients, which was interpreted to reflect impaired preparation for gait initiation probably due to diminished thalamic facilitating input to SMA in the patients. Larger cortical activity with gait initiation as compared with simple foot movement was also demonstrated in externally cued condition. Namely, by recording contingent negative variation $(\mathrm{CNV})$ in a simple reaction time paradigm with an inter-stimulus interval of $2 \mathrm{~s}$, Yazawa et al. (1997) found that late CNV starting about $1 \mathrm{~s}$ before the imperative stimulus was significantly larger at the midline fronto-central region before the gait initiation than before simple foot dorsiflexion. Since the generators of the late CNV include SMA, M1, and basal and mesial prefrontal areas (Hamano et al., 1997), the above finding also supported the important role of SMA in gait initiation.

Single photon emission computed topography (SPECT), which allows the use of radioisotope of a long half-life as a radiotracer, has been applied to the 
study of daily behavior like micturition and walking (Fukuyama et al., 1996, 1997). By the use of SPECT in normal subjects while walking, Hanakawa et al. (1999b) observed the rCBF increase in the foot and trunk area of S1-M1, SMA, lateral PMA and cingulate gyrus in addition to dorsal brainstem and cerebellum. In patients with Parkinson's disease of mild to moderate disability, the gait-associated activation was significantly smaller in the right SMA, left precuneus and right cerebellar hemisphere as compared with the age-matched normal subjects (Hanakawa et al., 1999b). These findings are difficult to be correlated with the BP study by Vidailhet et al. (1993) because of different temporal resolution of the two techniques. The BP study was able to discuss the activity before the initial stepping movement while the SPECT study investigated overall activity throughout the experimental session of walking.

Hanakawa et al. (1999a) extended their study to investigate the possible mechanism underlying the phenomenon called 'kinesie paradoxale', which is characterized by an improvement of frozen gait by special visual input. They studied patients with mildly to moderately disabled Parkinson's disease and age-matched normal subjects with SPECT, comparing two conditions; one walking across transverse lines and the other walking along parallel lines, each drawn on a treadmill which moved at a constant speed. As the result, Parkinson patients showed marked improvement of gait parameters with the transverse lines compared with the parallel lines, and the increased $\mathrm{rCBF}$ activation in the right lateral PMA with the transverse lines compared with the parallel lines was significantly larger in the patient group than in the control group (Hanakawa et al., 1999a). It was postulated that the lateral PMA, which is relatively spared in Parkinson's disease and receives abundant visual information from parietal cortex, is switched on by special visual input to facilitate the movement initiation, while the self-initiated movement mainly controlled by SMA remains inactivated due to decreased thalamic facilitating input to SMA as the result of striatal dopaminergic deficiency (Hanakawa et al., 1999a; Shibasaki et al., 2004).

\section{b. Cortical activities associated with swallowing}

Satow et al. (2004) recorded MRCP with self-initiated swallowing and compared with self-initiated tongue protrusion in normal subjects. For swallowing, the subjects kept 2-3 $\mathrm{ml}$ of water in the mouth for 5-10 s and 
swallowed as briskly as possible with the jaw relaxed and slightly open. For the task of tongue protrusion, the subjects kept the same mouth position without water and protruded the tongue at a self-paced interval of 10-20 s. They found a BP before swallowing which was similar to the BP before tongue protrusion except that $\mathrm{BP}$ occurred earlier in swallowing than in tongue protrusion. BP before swallowing was largest at the midline vertex and lateralized to either hemisphere depending on the subject. They also recorded MRCP in association with swallowing with subdural electrodes in patients with medically intractable partial epilepsy as a part of pre-surgical evaluation. As the result, BP occurred at the face/tongue area of S1-M1 and SMA with both swallowing and tongue protrusion although there was inter-individual variability (Satow et al., 2004).

\section{c. Cortical activities associated with praxis movements}

Clinical observation of patients with ideational or ideomotor apraxia suggests an important role of the parietal cortex and its connection to the frontal cortex of the dominant hemisphere in preparation and execution of praxis movements employed for daily activities. Wheaton et al. (2005a) recorded MRCP associated with pantomiming of common gestures or tool use in normal right-handed subjects. BP preceding these praxis movements was found to start at the parietal region, larger over the left, and then followed by the $\mathrm{BP}$ over the midline frontal region and bilateral central regions. By analyzing ERD of EEG $\beta$ band (18-22 Hz) associated with the praxis movements, the activation was also found to start from the left parietal region (Wheaton et al., 2005a). By further analyzing the movement-related cortico-cortical coherence against the left frontal region, they showed increased functional coupling between the left parietal area and the left frontal area during preparation and execution of those praxis movements (Wheaton et al., 2005b). Specific activation of the left parietal cortex in reaching movement was also demonstrated by recording BP in epilepsy patients as a pre-surgical evaluation with subdural electrodes covering the left parietal cortex (Inouchi et al., 2008).

In order to elucidate the mechanism of grasping that is the most primitive and essential movement of human, the author's group carried out an event-related fMRI study on the judgment of graspability of visually presented objects in healthy subjects. In that study, normal subjects were 
asked to judge whether a visually presented object was graspable in one hand or not. The event-related fMRI allowed us to present graspable and non-graspable objects in the same session at a random sequence and yet to analyze the data separately. As the result, a greater activation when the object was judged graspable as compared with non-graspable was found at two discrete areas in the left inferior parietal lobule (IPL), one at the dorsal IPL extending to the intraparietal sulcus and the other at the ventral IPL, and a small area in the ventral PMA (Hattori et al., 2009) (Fig. 1a).

Furthermore, a psychophysiological interaction analysis showed that these two regions in the left IPL had similar but discrete functional connectivity to the left lateral and mesial frontal cortices (Hattori et al., 2009) (Fig. 1b). This task-specific parieto-frontal connectivity is compatible with the clinical concept of apraxia caused by lesion of the left parieto-frontal pathway. In relation to this particular task, the left dorsal IPL had functional connectivity to the left ventral PMA, SMA and right cerebellar cortex, whereas the left ventral IPL had functional connectivity to the left dorsolateral prefrontal cortex and pre-SMA (Fig. 1b). Based on these findings, it was postulated that the connection from the left dorsal IPL is specifically associated with automatic flow of information about grasping behavior. By contrast, the connection from the left ventral IPL might be related to motor imagination or enhanced external attention to the presented visual stimuli (Hattori et al., 2009).

\section{Mechanism of voluntary motor inhibition}

a. Negative motor area vs. inhibitory motor area

Based on the data obtained by electrical stimulation of cerebral cortex, two different groups of cortical areas have been shown to suppress movements. One is 'negative motor area' described by Luders and his group. By stimulating cortical areas with subdural electrodes at $50 \mathrm{~Hz}$ for $5 \mathrm{~s}$ or less, the negative motor area was defined as the area which interfered with tonic muscle contraction or rapid alternating movements (Luders et al., 1995). The main negative motor areas were originally found in the inferior frontal gyrus rostral to the face are of M1 (primary negative motor area) and in the area rostral to the SMA proper (supplementary negative motor area). Later the negative motor area was found to be distributed more widely in the PMA (Mikuni et al., 2006). The other group is 'inhibitory motor area' which 
causes transient interruption of ongoing EMG discharge (asterixis) upon a single pulse electrical stimulation (Ikeda et al., 2000; Rubboli et al., 2006). In contrast with the negative motor area, the inhibitory motor areas are localized to the peri-rolandic cortex. Clinically, hyperexcitability of the inhibitory motor area causes epileptic negative myoclonus (Noachtar et al, 1997) or cortical (reflex) negative myoclonus (Shibasaki et al., 1994). In contrast, epileptogenic involvement of the negative motor area causes motor arrest without apparent motor paralysis (Ikeda et al., 2009). As the terminology of negative motor area vs. inhibitory motor area is confusing, in this review article the two areas were defined as described above following the original publication of each category.

\section{b. Voluntary motor inhibition}

In order to investigate a possible role of the inhibitory motor areas in voluntary motor inhibition, the author's group investigated cortical activities associated with self-initiated interruption of ongoing muscle contraction or self-initiated muscle relaxation in normal subjects. The subjects were trained so that the movement was caused by pure muscle relaxation without involving contraction of any antagonist or related muscles. By adopting the onset of EMG silent period induced by self-initiated muscle relaxation as a trigger for back averaging EEG, it was found that the voluntary muscle relaxation was preceded by a slow, surface-negative EEG potential which was identical to the BP preceding voluntary muscle contraction in terms of waveform, distribution and timing (Terada et al., 1995a, 1999). BP arising from SMA before voluntary muscle relaxation was also demonstrated by epicortical recording in epilepsy patients in whom the mesial frontal cortex was evaluated before surgical treatment (Yazawa et al., 1998). The presence of inhibitory areas in S1-M1 was also demonstrated by analysis of ERD/ERS based on MEG recording (Toma et al., 2000) as well as by an event-related fMRI study (Toma et al., 1999).

The fMRI study of voluntary muscle relaxation showed activation in the pre-SMA, SMA proper and the contralateral S1-M1 just like the case of voluntary muscle contraction. In fact the activation of the mesial frontal region (pre-SMA and SMA proper) was greater in the muscle relaxation than in the muscle contraction task (Toma et al., 1999). The presence of both BP and active hemodynamic change preceding voluntary motor inhibition 
similar to those found before voluntary muscle contraction suggests an increase of excitatory postsynaptic potential (EPSP), an active process, rather than an inhibitory, negative process in the cortical neurons (Shibasaki, 2008). In view of the fact that no pyramidal tract cells are known to directly inhibit anterior horn cells, it is postulated that voluntary motor inhibition is caused by activation of inhibitory interneurons at the spinal cord. This notion holds true for negative involuntary movement such as cortical negative (reflex) myoclonus, because it is preceded by a spike discharge in the corresponding part of M1, which will be discussed in Section 9a.

5. Cortical activities associated with motor imagination

An important question often asked is how cortical activities are different when the movement is just imagined without active motor execution. Jankelowitz and Colebatch (2002) compared averaged EEG potentials recorded at the central vertex electrode $(\mathrm{Cz})$ in motor imagination, cued movement to a tone presented at a fixed interval and self-initiated movement, and observed early BP equally in all of the three conditions for shoulder movement as well as for finger movement (Fig. 2a). Late BP was seen before the actual movement execution regardless of whether self-initiated or cued, but it was small, if any, before the imagined movement. Late BP for the movement execution and cued movements was larger in the shoulder movement than in the finger movement, which is most likely because the $\mathrm{Cz}$ electrode is closer to the shoulder area of M1 and that of the lateral PMA than to the corresponding finger areas. This assumption is based on the fact that the late BP recorded from the scalp electrodes is mainly generated by M1 and the lateral PMA contralateral to the movement with precise somatotopy (Shibasaki and Hallett, 2006).

Brain areas activated by motor imagery have been compared with motor execution by several investigators using fMRI. Kuhtz-Buschbeck et al. (2003) reported that SMA and the left dorsal and ventral PMA were activated during motor imagery regardless of the side of hand movement and regardless of the task complexity. Cunnington et al. (2005) found that SMA was active both in imagination and motor execution whereas MI was active only in motor execution, supporting an important role of SMA in motor imagery (Fig. 2b). Although M1 does not seem to be significantly active 
before or during motor imagery, it is noteworthy that there is excitability change in M1 before or during motor imagery if evaluated by TMS.

Kuhtz-Buschbeck et al. (2003) showed that the M1 excitability was increased during motor imagery of complex, but not simple, motor task. Kumru et al. (2008), in the simple reaction task, showed excitability increase of M1 just before motor imagery (cued by the imperative stimulus) as well as before actual motor execution.

Hanakawa et al. (2003) used fMRI to compare the functional neuroanatomy of motor execution and imagery using a task which objectively assessed imagery performance. They found imagery-predominant activation in the precentral sulcus at the level of middle frontal gyrus and in the posterior superior parietal cortex/precuneus. Among others, activity of the superior precentral sulcus and intraparietal sulcus areas, predominantly on the left, was associated with accuracy of the imagery. In contrast, the motor-predominant activity was found in the S1-M1, parietal operculum, anterior cerebellum, caudal PMA and area 5. As for SMA, they found activation equally in both motor imagery and execution. Different results among different studies might depend on the experimental paradigm, especially how much visual factor is involved in the motor imagery.

Recently Kimura's group has made an interesting observation on the effect of voluntary effort, either facilitating or inhibiting, on $\mathrm{F}$ wave which directly reflects excitability of anterior horn cells at the spinal cord. In their experiments in normal subjects, specific instruction to volitionally relax the immobilized muscle suppressed not only MEP but also F waves, and imagination to move the corresponding part of the body countered the rest-induced suppression of $\mathrm{F}$ waves (Taniguchi et al., 2008; Fujisawa et al., 2011). Hence it is important to keep in mind that MEP changes even produced by mental activity may still occur primarily at the spinal cord level. In this case, however, it might be possible that changes of the anterior horn cell excitability might have resulted from a long-standing influence, either facilitating or inhibiting, of cortical mental activity on the anterior horn cells, producing a kind of plastic change at the spinal level.

\section{Will to move and significance of BP}

A question as to where in the brain and when the conscious intention to move occurs has drawn increasing attention of many investigators. In 
Libet's well-known experiment in which the subjects were requested to recall the position of a fast-rotating clock hand when they first felt that they wanted to move their hands, the intention to move was found to occur as close as $200 \mathrm{~ms}$ to the movement onset (Libet et al., 1983). This timing was even later than the onset of the late BP. Deecke and Kornhuber (2003) interpreted this finding in three steps as follows. First, there is a general decision to move periodically in the beginning of the whole experiment. Second, it is then possible that the decision for each individual movement is made subconsciously and that consciousness is "switched on" about $200 \mathrm{~ms}$ before the movement onset. Third, this $200 \mathrm{~ms}$ interval gives time for consciousness to veto the movement.

Matsuhashi and Hallett (2008) developed a unique experimental paradigm. In their study, normal subjects were instructed to make brisk extension of index finger as soon as the thought of the movement came to their mind and to repeat it at a self-paced rate of once every 5-10 s while tone stimuli were presented pseudo-randomly at intervals of $3-20 \mathrm{~s}$. The subjects were instructed to stop the movement if they heard the tone after they started thinking about the movement ('Veto' of Fig. 3a). However, if the tone was presented too close to the movement onset or too late after the subjects started thinking about the movement, the movement can no longer be vetoed ('No return' of Fig. 3a). If the tone was heard while they were not thinking about the next movement, they just ignored the tone ('Ignore' of Fig. 3a). Then the distribution of relative times between tones and movements was analyzed, and the time of intention was estimated. By this new method which depends on the subject's real-time decision of whether or not there was a thought to move when a tone occurred without involving the subject's recall and self-reporting, it was found that the mean time of the conscious intention to move was $1.42 \mathrm{~s}$ before movement (Fig. 3b), which is still later than the onset of early BP but earlier than the onset of late BP.

As the slow surface-negativity is considered to arise from increasing depolarization of the superficial layer of the apical dendrites of pyramidal neurons (Shibasaki, 2008), it seems reasonable to postulate that the early BP might reflect subconscious readiness for the forthcoming movement while the late BP might be related to the conscious will to move.

7. Movement-related cortical potentials in pathological conditions 
MRCP has been studied in various pathological conditions, especially in patients with movement disorders including Parkinson's disease, cerebellar ataxia, mirror movement, stroke recovery, focal dystonia, and psychogenic movement disorders (Shibasaki and Hallett, 2006). Although various abnormalities of BP have been reported in the above pathological conditions, most of them were of academic interest in relation to pathophysiology of each condition. When it comes to each individual case, however, diagnostic significance of BP was rather small.

In this regard, recording of $\mathrm{BP}$ has been shown to be clinically useful in patients with psychogenic involuntary movements. By adopting the onset of involuntary movement as a fiducial point for back averaging EEG (see Section 8 for the detail of jerk-locked back averaging), Terada et al. (1995b) demonstrated a BP-like activity before myoclonic jerk that was clinically diagnosed psychogenic. In fact, the activity was similar to BP recorded preceding the volitional movement of the same kind mimicked by the patient. Therefore, if a surface-negative slow potential similar to BP is demonstrated preceding the movement in question, it might support possible participation of voluntary mechanism in the generation of that movement (Fig. 4). In patients with Tourette's syndrome who often confess urge to move before the tics, some tics might be involuntary but some might be preceded by conscious intention to move. By applying the back-averaging technique to patients with Tourette's syndrome, Obeso et al. (1981) did not find any EEG activity before the tics while they found normal BP before the movements mimicking the tics. Later Karp et al. (1996), by using the same method of back averaging EEG, observed a potential resembling late BP before the tics in two out of their five patients with simple motor tics.

\section{Jerk-locked back averaging}

One day in 1975, the author was recording MRCP associated with self-paced finger movement in a patient with progressive myoclonus epilepsy due to sialidase deficiency as a part of the electrophysiological study of myoclonus. At that time, the author was interested in the observation that BP was significantly small or even absent in patients with cerebellar lesion, especially in those with a lesion involving the cerebellar efferent pathway or dentato-thalamic tract (Shibasaki et al., 1978, 1986; Ikeda et al., 1994; Kitamura et al., 1999). While watching the data of on-line back averaging 
of EEG on the computer display, the author noticed of a sharp biphasic waveform on the averaged EEG instead of a slow negative potential culminating into a steeper slope which was expected to be seen toward the onset of voluntary movement. The sharp EEG potential was maximal at the central region contralateral to the hand from which the surface EMG was recorded and it preceded the onset of the averaged EMG by $15-20 \mathrm{~ms}$. Looking back at the raw EEG-EMG polygraphic record, it was discovered that, during the experimental session, the back-averaging program happened to be triggered by EMG discharges associated with myoclonus instead of voluntary muscle contraction (Shibasaki and Kuroiwa, 1975). Thus, it was a serendipitous observation which might have been overlooked if the author himself was not doing the study. This technique was later named jerk-locked (back) averaging and has been widely used for the study of various involuntary movements.

\section{Cortical activities associated with involuntary movements}

Involuntary movements vary widely from a simple muscle contraction seen in cortical myoclonus to a complex movement like chorea, dyskinesia and athetosis. Among those involuntary movements, abnormalities of S1-M1 have been extensively investigated in cortical myoclonus, tremor and focal dystonia.

\section{a. Cortical myoclonus}

Myoclonic jerks originating from M1 (cortical myoclonus), especially those seen in patients with progressive myoclonus epilepsy, are often associated with a spike discharge on EEG, but it is difficult to know precisely the time and spatial relationship between the EEG spike and the myoclonus on the conventional EEG-EMG polygraph. In this regard, the jerk-locked back averaging (see Section 8 ) is effective in most cases. Cortical myoclonus is electrophysiologically characterized by a preceding spike arising from the somatotopically corresponding part of M1, a pathologically enhanced somatosensory evoked potential (giant SEP), and an exaggerated long latency, long loop reflex which was called C reflex by Sutton and Mayer (1974). The same electrophysiological findings were demonstrated also in patients with negative myoclonus of cortical origin (Shibasaki et al., 1994). MEG was effectively applied to the study of pathophysiology of cortical 
myoclonus (Uesaka et al., 1993, 1996; Kahru et al., 1994; Mima et al., 1998a, 1998b).

$\mathrm{C}$ reflex, a physiological correlate of cortical reflex myoclonus, is considered to be caused by pathological enhancement of a component (called LLR2, M2 or V2) of long loop reflex which is observed during sustained contraction of the corresponding muscle in normal subjects (Upton et al., 1971; Marsden et al., 1972; Lee and Tatton, 1975). Based on non-invasive, electrophysiological studies including MEG, mechanism of $\mathrm{C}$ reflex has been postulated to be transcortical via S1-M1 (Shibasaki et al., 1985; Mima et al., 1998b; Shibasaki and Hallett, 2005). Hitomi et al. (2006) studied a patient with focal cortical reflex myoclonus by using subdural electrodes placed on the corresponding area of S1-M1 as a part of pre-surgical evaluation, and observed temporal succession of giant SEP in the somatosensory area followed by activation of the corresponding motor area (Fig. 5). In response to tibial nerve stimulation, giant SEP was first seen at the foot area of S1, and $5 \mathrm{~ms}$ later it was followed by a giant potential at the foot area of M1. At the scalp electrode from which the SEP was simultaneously recorded, the two responses directly recorded from S1 and M1 were not distinguished, and instead a single response was observed with the latency nearly the same as that of the M1 response.

Excessively increased excitability of S1-M1 was postulated as the underlying pathophysiology of cortical (reflex) myoclonus or cortical (reflex) negative myoclonus (Shibasaki et al., 1985; 1994). Recent application of TMS, especially that of paired TMS, showed some evidence suggesting impairment of short-interval intracortical inhibition in M1 as an underlying cause of the hyperexcitability (Hanajima et al., 2008; Huang et al., 2008) (Fig. 6). However, the mechanism underlying the cortical hyperexcitability has not been fully elucidated.

Neuropathological correlate of cortical myoclonus is difficult to be determined because most cases of progressive myoclonus epilepsy present various neurological deficits such as cerebellar ataxia and dementia in addition to myoclonus. In this regard, a hereditary condition called benign adult familial myoclonus epilepsy or familial cortical myoclonic tremor with epilepsy is unique because of the relatively selective manifestation of myoclonus without other neurological deficits and only rare occurrence of generalized convulsion. Since 2004, investigators from Amsterdam have 
reported neuropathological findings in two cases of this condition. In their first case, loss of dendritic trees and somal sprouting with abnormal arborization were found exclusively in Purkinje cells of cerebellum, resembling the neuropathology of spinocerebellar ataxia type 6 (van Rootselaar et al., 2004). More recently, the same authors reported pathological findings in another case of this condition, which consisted of loss of Purkinje cells in addition to the above findings (van Rootselaar et al., 2007). If these pathological observations are specific for this condition, the cerebellar abnormality might be related to the reduced intracortical inhibition in M1. However, it has to be noted that, although the clinical picture looks similar among reported families of this unique condition, different genetic loci have been reported from different countries (Depienne et al., 2010). Therefore, the pathophysiology underlying cortical myoclonus may also differ among different families.

\section{b. Tremor}

Whether tremor is associated with cortical activities or not has been investigated by analyzing the correlation between the EMG oscillations associated with tremor and the EEG/MEG oscillations recorded from the corresponding central region of the scalp. By this method, the presence of cortico-muscular coherence at the tremor frequency has been documented for essential tremor (Hellwig et al., 2003), Parkinson tremor (Timmermann et al., 2003), and tremor in Wilson's disease (Sudmeyer et al., 2006) (Fig. 7). A question is often raised as to whether the cortico-muscular coherence at the tremor frequency might be a result of the kinesthetic feedback from the periphery to the sensory cortex. Govindan et al. (2006) used a theoretical model of essential tremor to investigate the direction of interaction between the cortical activity and EMG by analyzing time-delay and partial coherence. They showed that the cortical activity leads the muscle activity, suggesting that the coherence is not a result of kinesthetic feedback from the periphery to $\mathrm{S} 1-\mathrm{M} 1$ but the cortical activity is driving the tremor.

It is the current consensus that both essential tremor and Parkinson tremor have the pacemaker of oscillations in subcortical structures, most likely in the cerebellar circuit for essential tremor and in the striatum for Parkinson tremor (Krack et al., 2002; Molnar et al., 2005). In Parkinson's disease, rhythmic oscillation of the tremor frequency was demonstrated in 
the local field potential (LFP) recorded from the subthalamic nucleus (STN), and there was a significant coherence between STN-LFP and the EMG of the contralateral forearm at the tremor frequency (Marsden et al., 2001; Wang et al., 2006; Amtage et al., 2008). It has been postulated that the STN oscillation represents an oscillator of the tremor rather than the arrival of tremor-related input from the periphery. As for essential tremor, there has been no report of direct recording of neuronal discharges from the cerebellum itself in the patients because deep brain stimulation of cerebellar structures has never been applied for clinical use.

Regarding the thalamic relay nucleus of those tremor oscillations, it has been generally accepted that nucleus ventralis intermedius (Vim) is the main cerebellar receiving area whereas nucleus ventralis oralis posterior (Vop) is the main pallidal receiving area (Krack et al., 2002). When LFP is recorded from these structures in patients with tremor, however, correlation of these thalamic nuclei with the kind of tremor is not straightforward. In fact, regardless of the kind of tremor, whether Parkinson tremor or essential tremor, coherence with EMG was commonly found in both Vim and Vop (Marsden et al., 2000; Katayama et al., 2005; Kane et al., 2009).

It is well known that resting tremor in Parkinson's disease is suppressed by voluntary movement of the corresponding part of the body while postural/action tremor seen in patients with essential tremor and in those with lesion of the dentato-thalamic pathway is aggravated by voluntary movement or even by intention to move. There has been no satisfactory explanation for how voluntary movement suppresses resting tremor in Parkinson's disease. Kinoshita et al. (2010) investigated the time relationship between the suppression of resting tremor of the hand and the occurrence of $\mathrm{BP}$ associated with voluntary movement of the ipsilateral shoulder in patients with Parkinson's disease, and showed that clear suppression of resting tremor by voluntary movement was associated with earlier occurrence of $\mathrm{BP}$ with respect to the movement onset while poor suppression of resting tremor was associated with later occurrence of BP. Analysis of cortical activities in the frequency domain under various conditions might be of some interest for solving the above question. If we assume that the resting tremor occurs in a synchronized state of neuronal activities in S1-M1 at the tremor frequency, voluntary activation of the corresponding area of M1 might desynchronize that oscillation, thus 
suppressing the tremor.

\section{c. Focal dystonia}

Focal dystonia includes blepharospasm, embouchure dystonia, cervical dystonia, writer's camp and musician's cramp. It is usually task-specific and often improves by special sensory stimulus (sensory trick). In contrast with myoclonus and tremor as discussed above, a number of physiological abnormalities of S1-M1 have been reported in focal dystonia. Just to mention the classical representative literature, the somatotopic organization of fingers was shown to be disorganized in S1 contralateral to the affected hand (Muente et al., 2002). In motor cortices, impairment of inhibition was demonstrated by various techniques. By the use of paired pulse TMS, short-interval intracortical inhibition (Ridding et al., 1995) and surround inhibition (Sohn and Hallett, 2004) were shown to be impaired. In terms of voluntary motor inhibition, BP associated with voluntary muscle relaxation was shown to be small over the central region of the affected hemisphere in patients with focal hand dystonia (Yazawa et al., 1999). In an fMRI study in patients with writer's cramp, smaller volumes of the SMA proper and S1-M1 were activated in voluntary muscle contraction as well as relaxation of the affected (right) hand compared with normal control subjects (Oga et al., 2002). Furthermore, disturbance of sensorimotor integration has been documented as a task-specific decrease in amplitude of CNV (Kaji et al., 1995; Ikeda et al., 1996b), abnormal pre-movement gating of somatosensory input (Murase et al., 2000), and abnormal MEG-EMG coherence (Tecchio et al., 2008). Neuroimaging techniques have been extensively applied to the study of motor circuit functions in focal dystonia (see Zoons et al., 2011 for review). Thus, physiological abnormalities in focal dystonia are summarized as disorganization of S1, impaired cortical inhibition in M1, and abnormal sensorimotor integration. However, no standard, integrated interpretation of those data has been reached. Some of these abnormalities might be related as a cause of dystonia while others may be the outcome of long-standing presence of dystonia. As experimentally demonstrated in monkeys (Byl et al., 1997), a plastic change in S1-M1 seems to play an important role in the generation of task-specific focal dystonia like musician's cramp (Altenmuller and Jabusch, 2010). 


\section{d. Asterixis in thalamic lesion}

Patients with vascular lesion involving the lateral thalamus often show negative myoclonus or asterixis in the contralateral hand (Tatu et al., 2000). The underlying mechanism, especially whether it arises directly from the thalamus or it is mediated by S1-M1, has not been clarified. Recently the author's group obtained some data suggesting the participation of S1-M1 in its generation in two cases of thalamic infarction (Kojima et al., 2010). Namely, the averaged EEG time-locked to the onset of the asterixis revealed increased rhythmic oscillations of $15-18 \mathrm{~Hz}$ over the central region contralateral to the affected hand. Furthermore, the silent period-locked power change of EEG was increased at $B$ band in the corresponding central area. As the ERS is believed to represent inhibition or deactivation of the corresponding cortex (Pfurtscheller and Neuper, 2003; Pfurtscheller, 2006), the above finding suggests increased inhibition in S1-M1. Furthermore, the silent period induced by TMS during tonic muscle contraction was increased in duration in the affected hand compared with the intact hand. These findings suggest increased inhibition in S1-M1 ipsilateral to the thalamic lesion. It is therefore postulated that the asterixis seen in cases of thalamic lesion might be caused by the increased inhibition of S1-M1 as the result of the thalamic lesion, although the mechanism as to how the thalamic lesion inhibits S1-M1 remains to be solved.

\section{Integration}

Cortical activities associated with voluntary movement have been studied by using a number of non-invasive techniques in humans.

Electrophysiologically, MRCP, especially BP consisting of early BP and late $\mathrm{BP}$, movement-locked change of cortical oscillations (ERD and ERS), and correlation of oscillatory activities between cortex and muscle (cortico-muscular coherence) have been employed. Based on the hemodynamic principle, SPECT, PET and fMRI have been used depending on the characteristics and availability of each technique. Although experimental studies suggest that the hemodynamic response is significantly correlated to the neuronal activity (neurovascular coupling), especially to LFP (synaptic activity) rather than spiking activity, within a certain range, electrophysiological techniques provide higher temporal information than neuroimaging techniques and vice versa for the spatial information 
(Shibasaki, 2008). As discussed in this review article, both groups of techniques have been effectively applied to and have complemented each other in the study of mechanisms underlying voluntary and involuntary movements. Electrophysiological analysis in the time domain, owing to its high temporal resolution, has been especially useful for elucidating the generating mechanism of abrupt, instantaneous movements like myoclonus.

The mainstream of electrophysiological studies of cortical activities associated with voluntary movement consists of the time-domain analysis of field potentials like BP and the frequency-domain analysis of rhythmic oscillations like ERD. As discussed in Section $2 \mathrm{~b}$ in relation to pre-movement activity, the data derived from these two different principles are not necessarily in conformity (Babiloni et al., 1999; Bai et al., 2005). This is probably due to the different physiological mechanisms underlying generation of the field potential and the rhythmic oscillations. Bai et al. (2006) studied both BP and movement-related ERD in patients with primary lateral sclerosis and found marked decrease in BP but normal ERD. In view of the neuropathological abnormality of this condition consisting of selective degeneration of large pyramidal cells in M1, the above finding is in conformity with the notion that BP is generated by the pyramidal cells while ERD reflects activities of other cells, e.g. interneurons.

Application of TMS to physiological investigation of mechanism of voluntary motor control and of pathophysiology of involuntary movements provided useful information about the state of cortical excitability or inhibition. However, since the mechanism of cortical activation by TMS is expected to differ significantly from that of voluntary cortical activation, and probably also differ from spontaneous, abnormal activation like cortical myoclonus, TMS data should be carefully correlated with the results obtained by other electrophysiological techniques.

Epicortical recording with subdurally placed electrodes in patients with medically intractable partial epilepsy as a part of pre-surgical evaluation has provided useful information, supporting many of the findings obtained by the non-invasive techniques regarding both the central mechanism of voluntary movements and the pathophysiology of involuntary movements. It has to be kept in mind, however, that, in the epicortical recording, the area covered by the subdural electrodes is limited and the time allotted for the experiment is short for practical reason. Furthermore, in the clinical setting, recording 
with subdural electrodes is not possible to pick up the electrical potentials directly from the cortical sulcus.

Voluntary movement is prepared and executed with sequential activation of the pre-SMA and SMA proper bilaterally, and then the lateral premotor cortex and M1 with contralateral predominance in this order. Although BP may not directly represent conscious will to move (Libet et al., 1983; Matsuhashi et al., 2008), SMA, as a generator of earliest BP at least for simple movement, plays an important role in conscious initiation of the movement. SMA is more activated with complex sequence of muscle contraction compared with simple movement (Orgogozo and Larsen, 1979; Roland et al., 1980; Deiber et al., 1991; Grafton et al., 1992; Kitamura et al., 1993b; Shibasaki et al., 1993). Furthermore, SMA was shown to play an important part in motor imagination (Jankelowitz and Colebatch, 2002; Kuhtz-Buschbeck et al., 2003; Cunnington et al., 2005). All these facts suggest that, as originally suggested by Orgogozo and Larsen (1979), SMA is not really 'supplementary' or 'secondary', but 'supramotor'. Lateral PMA is perhaps in between SMA and M1, although lateral PMA is more sensitive to incoming stimuli than SMA as shown in the study of kinesie paradoxale in Parkinson's disease (see Section 3a) (Hanakawa et al., 1999).

S1-M1, the origin of the final common pathway for voluntary movements, has also been shown to be involved in the generation of some involuntary movements, especially cortical myoclonus, tremor and focal dystonia. The way of its involvement, however, is different among these three kinds of involuntary movements. Cortical myoclonus, regardless of whether spontaneous or induced by sensory stimuli, originates directly from M1 based on the hyperexcitability of S1-M1. Essential tremor and Parkinson tremor were both shown to be correlated with rhythmic oscillations of S1-M1 as well as those of motor relay nuclei of the thalamus at each tremor frequency. In these cases, the pace of rhythmic oscillations is believed to arise from subcortical structures, namely the cerebellar circuit for essential tremor and the striatum for Parkinson tremor, and S1-M1 is considered to serve as a relay center of the oscillations. Thus, at least these two kinds of tremor are passively driven by S1-M1 in contrast with the cortical myoclonus that is actively driven by M1. In contrast, focal dystonia is also considered to be mediated by S1-M1 and corticospinal tract as its final common pathway, but its cortical pathophysiology seems much more complex compared with 
cortical myoclonus and tremor. Focal dystonia is believed to involve wider cortical areas than S1-M1, including SMA and lateral PMA, and among others, disturbance of the sensorimotor integration is considered to play a major role in its generation.

Regarding other involuntary movements such as chorea, ballism, dyskinesia and athetosis, all of which are known to be caused by pathological or pharmacological impairment of basal ganglia, they may be also mediated by S1-M1. Paroxysmal kinesigenic or non-kinesigenic dyskinesia is of particular interest as to whether it is due to epileptic abnormality of basal ganglia origin or not. Ictal SPECT study in some cases showed hyperperfusion in the striatum and thalamus contralateral to the side of main involvement during the attacks (del Carmen Garcia, et al. 2000), but others reported hypoperfusion in the contralateral basal ganglia.

Involuntary movements are influenced by voluntary movement, conscious will to move and motor attention, but its mechanism has not been fully clarified. For example, mechanisms as to how resting tremor in Parkinson's disease is suppressed by voluntary movement of the corresponding part of the body and how it is aggravated by voluntary movement of other parts of the body remain to be clarified. As discussed in Section 9b, if we assume that the resting tremor occurs in a synchronized state of neuronal activities in S1-M1 at the tremor frequency, voluntary activation of the corresponding area of M1 might desynchronize that oscillation, thus suppressing the tremor. By contrast, voluntary movement of other parts of the body or 'motor distraction' might increase synchronization of the activity in the corresponding part of S1-M1. This hypothesis, however, may be difficult to be applied to postural tremor or action tremor seen in patients with essential tremor or lesions of the dentato-thalamic tract. Thus, a question arises as to how voluntary movement or even conscious intention to move aggravates the postural or action tremor. In this regard, physiological studies in the frequency domain regarding the effect of motor execution or motor imagery might add some more information to the understanding of this important issue.

Negative motor phenomena have drawn an increasing attention of many investigators in terms of both voluntary and involuntary movements. M1 is involved in both voluntary motor inhibition and in the generation of cortical (reflex) negative myoclonus with somatotopic organization, although 
voluntary motor inhibition involves wider areas including SMA and PMA in addition to M1. It is most likely that these inhibitory phenomena result from voluntary or pathological excitation of cortical areas in the peri-rolandic region, which produces epileptic negative myoclonus (Noachtar et al., 1997) or cortical (reflex) negative myoclonus (Shibasaki et al., 1994) in pathologically hyperexcitable condition. In view of the topographic distribution, these areas are most likely the areas which cause transient interruption of ongoing EMG discharge upon a single pulse electrical stimulation (Ikeda et al., 2000; Rubboli et al., 2006). In contrast with the above 'inhibitory motor area', 'negative motor area' was defined by Luders et al. (1995) as the area which, upon electrical stimulation of overlying subdural electrodes at $50 \mathrm{~Hz}$ for $5 \mathrm{~s}$ or less, interferes with ongoing tonic muscle contraction or rapid alternating movements. Main negative motor areas were found in two cortical regions, one located rostral to the face motor area in the inferior frontal gyrus (primary negative motor area) and the other in the rostral SMA (supplementary negative motor area) (Luders et al., 1995). Clinically epileptogenic involvement of these areas manifests motor arrest or limb-kinetic apraxia without overt muscle weakness (Ikeda et al., 2009). Thus, these two kinds of motor suppressing areas are different in terms of the way of electrical stimulation used for its identification, distribution and functions, but further study is warranted for elucidating the precise functions of these areas. The terminology of these two motor suppressing areas, 'inhibitory' and 'negative', is confusing and should be better defined.

The primary negative motor area as discussed above is also noteworthy in relation to the mirror neuron system. Mirror neurons are mainly localized to the caudal part of the inferior frontal gyrus (F5 of monkey), similar location to the primary negative motor area (Mikuni et al., 2006), and are engaged in understanding of actions and intentions of other individuals (Rizzolatti and Fabbri-Destro, 2010). Supplementary negative motor area is located just rostral to the SMA proper (Yazawa et al., 2000), and it corresponds to F6 of monkey. In view of the fact that F5 and F6 have dense neuronal connections in monkey, these two negative motor areas in human might be related to the mirror neuron system. Matsumoto et al. (2007), by recording cortico-cortical evoked potentials with subdural electrodes in epilepsy patients, showed the neuronal connection between the primary and 
supplementary negative motor areas in human. Since the mirror neuron function was also found in the parieto-frontal circuit (Rizzolatti and Sinigaglia, 2010), the parieto-frontal connectivity, which was demonstrated by the fMRI study on the judgment of graspability (Section 3c) (Hattori et al., 2009) and by cortico-cortical evoked potential (Matsumoto et al., 2011), might be also related to functions of the mirror neuron system. Study on the connectivity between the two negative motor areas in the frontal lobe and on the parieto-frontal circuit might open a new field of clinical neuroscience related to higher motor control system in human.

\section{References}

Altenmuller E, Jabusch HC. Focal dystonia in musicians: phenomenology, pathophysioloy and triggering factors. Eur J Neurol 2010;17 (Suppl 1):31-6.

Amtage F, Henschel K, Schelter B, Vesper J, Timmer J, Lucking CH, et al. Tremor-correlated neuronal activity in the subthalamic nucleus of Parkinsonian patients. Neurosci Lett 2008;442:195-9.

Babiloni C, Carducci F, Cincotti F, Rossini PM, Neuper C, Pfurtscheller G, et al. Human movement-related potentials vs. desynchronization of EEG alpha rhythm: a high-resolution EEG study. NeuroImage 1999;10:658-65.

Bai O, Mari Z, Vorbach S, Hallett M. Asymmetric spatiotemporal patterns of event-related desynchronization preceding voluntary sequential finger movements: a high resolution EEG study. Clin Neurophysiol 2005;116:1213-21.

Bai O, Vorbach S, Hallett M, Floeter MK. Movement-related cortical potentials in primary lateral sclerosis. Ann Neurol 2006;59:682-90.

Barrett G, Shibasaki H, Neshige R. A computer-assisted method for averaging movement-related cortical potentials with respect to EMG onset. Electroenceph Clin Neurophysiol 1985;60:276-81.

Barrett G, Shibasaki H, Neshige R. Cortical potentials preceding voluntary 
movement : Evidence for three periods of preparation in man. Electroenceph Clin Neurophysiol 1986;63:327-39.

Bates JAM. Electrical activity of the cortex accompanying movement. J Physiol 1951;113:240-57.

Benecke R, Dick JPR, Rothwell JC, Day BL, Marsden CD. Increase of the Bereitschaftspotential in simultaneous and sequential movement. Neurosci Lett 1985;62:347-52.

Brown P, Salenius S, Rothwell JC, Hari R. Cortical correlate of the Piper rhythm in humans. J Neurophysiol 1998;80:2911-7.

Byl NN, Merzenich MM, Cheung S, Bedenbaugh P, Nagarajan SS, Jenkins WM. A primate model for studying focal dystonia and repetitive strain injury: effects on the primary somatosensory cortex. Phys Ther 1997;77:269-84.

Conway BA, Halliday DM, Farmer SF, Shahani U, Maas P, Weir AI, et al. Synchronization between motor cortex and spinal motoneuronal pool during the performance of a maintained motor task in man. J Physiol (London) 1995;489:917-22.

Cunnington R, Windischberger C, Deecke L, Moser E. The preparation and execution of self-initiated and externally-triggered movement: a study of event-related fMRI. NeuroImage 2002;15:373-85.

Cunnington R, Windischberger C, Deecke L, Moser E. The preparation and readiness for voluntary movement: a high-field event-related fMRI study of the Bereitschafts-BOLD response. NeuroImage 2003;20:404-12.

Cunnington R, Windischberger C, Moser E. Premovement activity of the pre-supplementary motor area and the readiness for action: Studies of time-resolved event-related functional MRI. Human Mov Sci 2005;24:644-56.

Deecke L, Scheid P, Kornhuber HH. Distribution of readiness potential, pre-motion positivity, and motor potential of the human cerebral cortex preceding voluntary finger movement. Exp Brain Res 1969;7:158-68. 
Deecke L, Kornhuber HH. An electrical sign of participation of the mesial 'supplementary' motor cortex in human voluntary finger movement. Brain Res 1978;159:473-6.

Deecke L, Weinberg H, Brickett P. Magnetic fields of the human brain accompanying voluntary movement : Bereitschaftsmagnetfeld. Exp Brain Res 1982;48:144-8.

Deecke L, Boschert J, Weinberg H, Brickett P. Magnetic fields of the human brain (Bereitschaftsmagnetfeld) preceding voluntary foot and toe movements. Exp Brain Res 1983;52:81-6.

Deecke L, Lang W, Heller HJ, Hufnagl M, Kornhuber HH. Bereitschaftspotential in patients with unilateral lesions of the supplementary motor area. J Neurol Neurosurg Psychiatry 1987;50:1430-4.

Deecke L, Kornhuber HH. Human freedom, reasoned will, and the brain: The Bereitschaftspotential story. In: Jahanshahi M, Hallett M, editors. The Bereitschaftspotential. Movement-related cortical potentials. New York: Kluver Academic/Plenum Publishers; 2003, p. 283-320.

Deiber M-P, Passingham RE, Colebatch JG, Friston KJ, Nixon PD, Frackowiak RSJ. Cortical areas and the selection of movement: a study with positron emission tomography. Exp Brain Res 1991;84:393-402.

del Carmen Garcia M, Intruvini S, Vazquez S, Beserra F, Rabinowicz AL. Ictal SPECT in paroxysmal non-kinesigenic dyskinesia. Case report and review of the literature. Parkinson Rel Disord 2000;6:119-21.

Depienne C, Magnin E, Bouteiller D, Stevanin G, Saint-Martin C, Vidailhet M, et al. Familial cortical myoclonic tremor with epilepsy. The third locus (FCMTE3) maps to 5p. Neurology 2010;74:2000-3.

Erdler M, Beisteiner R, Mayer D, Kaindl T, Edward V, Windischberger C, et al. Supplementary motor area activation preceding voluntary movement is detectable with a whole-scalp magnetoencephalography system. NeuroImage 2000;11:697-707. 
Fujisawa R, Kimura J, Taniguchi S, Ichikawa H, Hara M, Shimizu H, et al. Effect of volitional relaxation and motor imagery on $\mathrm{F}$ wave and MRP: Do these tasks affect excitability of the spinal or cortical motor neurons? Clin Neurophysiol 2011;122:1405-10.

Fukuyama H, Matsuzaki S, Ouchi Y, Yamauchi H, Nagahama Y, Kimura J, et al. Neural control of micturition in man examined with single photon emission computed tomography using 99m-Tc-HMPAO. Neuroreport 1996;7:3009-12.

Fukuyama H, Ouchi Y, Matsuzaki S, Nagahama Y, Yamauchi H, Ogawa M, et al. Brain functional activity during gait in normal subjects: a SPECT study. Neurosci Lett 1997;228:183-6.

Gerloff C, Uenishi N, Nagamine T, Kunieda T, Hallett M, Shibasaki H. Cortical activation during fast repetitive finger movements in humans: steady-state movement-related magnetic fields and their cortical generators. Electroenceph Clin Neurophysiol 1998;109:444-53.

Govindan RB, Raethjen J, Arning K, Kopper F, Deuschl G. Time delay and partial coherence analyses to identify cortical connectivities. Biol Cybern 2006;94:262-75.

Grafton ST, Mazziotta JC, Woods RP, Phelps ME. Human functional anatomy of visually guided finger movements. Brain 1992;115:565-87.

Halliday DM, Conway BA, Farmer SF, Rosenberg JR. Using electroencephalography to study functional coupling between cortical activity and electromyograms during voluntary contractions in humans. Neurosci Lett 1998;241:5-8.

Hamano T, Luders HO, Ikeda A, Collura TF, Comair YG, Shibasaki H. The cortical generators of the continent negative variation in humans: a study with subdural electrodes. Electroenceph Clin Neurophysiol 1997;104:257-68. 
Hanajima R, Okabe S, Terao Y, Furubayashi T, Arai N, Inomata-Terada S, et al. Difference in intracortical inhibition of the motor cortex between cortical myoclonus and focal hand dystonia. Clin Neurophysiol 2008;119:1400-7.

Hanakawa T, Fukuyama H, Katsumi Y, Honda M, Shibasaki H. Enhanced lateral premotor activity during paradoxical gait in Parkinson's disease. Ann Neurol 1999a;45:329-36.

Hanakawa T, Katsumi Y, Fukuyama H, Hayashi T, Honda M, Kimura J, et al. Mechanisms underlying gait disturbance in Parkinson disease. A single photon emission computed tomography study. Brain 1999b;122:1271-82.

Hanakawa T, Immisch I, Toma K, Dimyan MA, van Gelderen P, Hallett M. Functional properties of brain areas associated with motor execution and imagery. J Neurophysiol 2003;89:989-1002.

Hattori N, Shibasaki H, Wheaton L, Wu T, Matsuhashi M, Hallett M. Discrete parieto-frontal functional connectivity related to grasping. J Neurophysiol 2009;101:1267-82.

Hellwig B, Schelter B, Guschlbauer B, Timmer J, Lucking CH. Dynamic synchronization of central oscillators in essential tremor. Clin Neurophysiol 2003;114:1462-7.

Hitomi T, Ikeda A, Matsumoto R, Kinoshita M, Taki J, Usui K, et al. Generators and temporal succession of giant somatosensory evoked potentials in cortical reflex myoclonus: Epicortical recording from sensorimotor cortex. Clin Neurophysiol 2006;117:1481-6.

Huang YZ, Lai SC, Lu CS, Weng YH, Chuang WL, Chen RS. Abnormal cortical excitability with preserved brainstem and spinal reflexes in sialidosis type I. Clin Neurophysiol 2008;119:1042-50.

Ikeda A, Luders HO, Burgess RC, Shibasaki H. Movement-related potentials recorded from supplementary motor area and primary motor area. Role of supplementary motor 
area in voluntary movements. Brain 1992;115:1017-43.

Ikeda A, Shibasaki H, Nagamine T, Terada K, Kaji R, Fukuyama H, et al. Dissociation between contingent negative variation and Bereitschaftspotential in a patient with cerebellar efferent lesion. Electroenceph Clin Neurophysiol 1994;90:359-64.

Ikeda A, Luders HO, Collura TF, Burgess RC, Morris HH, Hamano T, et al. Subdural potentials at orbitofrontal and mesial prefrontal areas accompanying anticipation and decision making in humans : a comparison with Bereitschaftspotential. Electroenceph Clin Neurophysiol 1996a;98:206-12.

Ikeda A, Shibasaki H, Kaji R, Terada K, Nagamine T, Honda M, et al. Abnormal sensorimotor integration in writer's cramp : Study of contingent negative variation. Mov Disord 1996b;11:683-90.

Ikeda A, Ohara S, Matsumoto R, Kunieda T, Nagamine T, Miyamoto S, et al. Role of primary sensorimotor cortices in generating inhibitory motor response in humans. Brain 2000;123:1710-21.

Ikeda A, Hirasawa K, Kinoshita M, Hitomi T, Matsumoto R, Mitsueda T, et al. Negative motor seizure arising from the negative motor area: Is it ictal apraxia? Epilepsia 2009;50:2072-84.

Inouchi M, Taki J, Kikuchi T, Mitsueda T, Matsumoto R, Mikuni N, et al. Human parietal reach region: an epicortical field potential recording for reaching. Neurology 2008;70 (Suppl 1):A124 (abstract).

Inoue M, Mima T, Kojima Y, Satoi H, Makino F, Kanda M, et al. A case presenting with both features of essential tremor and Parkinson tremor. Clin Neurol (in Japanese) 2007;47:413-8 (abstract available in English).

Jankelowitz SK, Colebatch JG. Movement-related potentials associated with self-paced, cued and imagined arm movements. Exp Brain Res 2002;147:98-107.

Kaji R, Ikeda A, Ikeda T, Kubori T, Mezaki T, Kohara N, et al. Physiological study of cervical dystonia. Task-specific anormality in contingent negative variation. Brain 
$1995 ; 118: 511-22$

Kane A, Hutchison WD, Hodaie M, Lozano AM, Dostrovsky JO. Enhanced synchronization of thalamic theta band local field potentials in patients with essential tremor. Exp Neurol 2009;217:171-6.

Karhu J, Hari R, Paetau R, Kajola M, Mervaala E. Cortical reactivity in progressive myoclonus epilepsy. Electroenceph Clin Neurophysiol 1994;90:93-102.

Karp BI, Porter S, Toro C, Hallett M. Simple motor tics may be preceded by a premotor potential. J Neurol Neurosurg Psychiatry 1996;61:103-6.

Katayama Y, Kano T, Kobayashi K, Oshima H, Fukaya C, Yamamoto T. Difference in surgical strategies between thalamotomy and thalamic deep brain stimulation for tremor control. J Neurol 2005;252 (Suppl 4):IV17-IV22.

Kinoshita M, Matsuhashi M, Nakagawa T, Nagamine T, Sawada H, Saiki H, et al. How does voluntary movement stop resting tremor? Clin Neurophysiol 2010;121:983-5.

Kitamura J, Shibasaki H, Kondo T. A cortical slow potential is larger before an isolated movement of a single finger than simultaneous movement of two fingers. Electroenceph Clin Neurophysiol 1993a;86:252-8.

Kitamura J, Shibasaki H, Takagi A, Nabeshima H, Yamaguchi A. Enhanced negative slope of cortical potentials before sequential as compared with simultaneous extensions of two fingers. Electroenceph Clin Neurophysiol 1993b;86:176-82.

Kitamura J, Shibasaki H, Terashi A, Tashima K. Cortical potentials preceding voluntary finger movement in patients with focal cerebellar lesion. Clin Neurophysiol 1999;110:126-32.

Kojima Y, Inoue M, Fumuro T, Matsuhashi M, Mima T, Ikeda A, et al. Cortical inhibition may be exaggerated in unilateral asterixis due to thalamic infarction. Clin Neurophysiol 2010;121 (Suppl 1):S243 (abstract).

Kornhuber HH, Deecke L. Hirnpotentialanderungen beim Menschen vor und nach 
Willkurbewegungen, dargestellt mit Magnetband-Speicherung und Ruckwartsanalyse. Pflugers Arch 1964;281:52.

Kornhuber HH, Deecke L. Hirnpotentialanderungen bei Willkurbewegungen und passiven Bewegungen des Menschen : Bereitschaftspotential und reafferente Potentiale. Pflugers Arch 1965;284:1-17.

Krack P, Dostrovsky J, Ilinsky I, Kultas-Ilinsky K, Lenz F, Lozano A, et al. Surgery of the motor thalamus: Problems with the present nomenclature. Mov Disord 2002;17 (Suppl 3):S2-S8.

Kuhtz-Buschbeck JP, Mahnkopf C, Holzknecht C, Siebner H, Ulmer S, Jansen O. Effector-independent representations of simple and complex imagined finger movements: a combined fMRI and TMS study. Eur J Neurosci 2003;18:3375-87.

Kumru H, Soto O, Casanova J, Valls-Sole J. Motor cortex excitability changes during imagery of simple reaction time. Exp Brain Res 2008;189:373-8.

Lang W, Cheyne D, Kristeva R, Beisteiner R, Lindinger G, Deecke L.

Three-dimensional localization of SMA activity preceding voluntary movement. A study of electric and magnetic fields in a patient with infarction of the right supplementary motor area. Exp Brain Res 1991;87:688-95.

Lee RG, Tatton WG. Motor responses to sudden limb displacements in primates with specific CNS lesions and in human patients with motor system disorders. Can J Neurol Sci 1975;2:285-93.

Libet B, Gleason CA, Wright EW, Pearl DK. Time of conscious intention to act in relation to onset of cerebral activity (readiness-potential). The unconscious initiation of a freely voluntary act. Brain 1983;106:623-42.

Luders H, Awad I, Burgess R, Wyllie E, Van Ness P. Subdural electrodes in the presurgical evaluation for surgery of epilepsy. Epilepsy Res Suppl 1992;5:147-56.

Luders HO, Dinner DS, Morris HH, Wyllie E, Comair YG. Cortical electrical stimulation in humans. The negative motor areas. Adv Neurol 1995;67:115-29. 
Marsden CD, Merton PA, Morton HB. Servo action in human voluntary movement. Nature 1972;238:140-3.

Marsden JF, Ashby P, Limousin-Dowsey P, Rothwell JC, Brown P. Coherence between cerebellar thalamus, cortex and muscle in man. Cerebellar thalamus interactions. Brain 2000;123:1459-70.

Marsden JF, Limousin-Dowsey P, Ashby P, Pollak P, Brown P. Subthalamic nucleus, sensorimotor cortex and muscle interrelationships in Parkinson's disease. Brain 2001;124:378-88.

Matsuhashi M, Hallett M. The timing of the conscious intention to move. Eur J Neurosci 2008;28:2344-51.

Matsumoto R, Nair DR, LaPresto E, Najm I, Bingaman W, Shibasaki H, et al. Functional connectivity in the human language system: a cortico-cortical evoked potential study. Brain 2004;127:2316-30.

Matsumoto R, Nair DR, LaPresto E, Bingaman W, Shibasaki H, Luders HO. Functional connectivity in human cortical motor system: a cortico-cortical evoked potential study. Brain 2007;130:181-97.

Matsumoto R, Nair DR, Ikeda A, Fumuro T, LaPresto E, Mikuni N, et al. Parieto-frontal network in humans studied by cortico-cortical evoked potential. Human Brain Map 2011 (in press).

Mikuni N, Ohara S, Ikeda A, Hayashi N, Nishida N, Taki J, et al. Evidence of a wide distribution of negative motor areas in the peri-rolandic cortex. Clin Neurophysiol 2006;117:33-40.

Mima T, Nagamine T, Ikeda A, Yazawa S, Kimura J, Shibasaki H. Pathogenesis of cortical myoclonus studied by magnetoencephalography. Ann Neurol 1998a;43:598-607.

Mima T, Nagamine T, Nishitani N, Mikuni N, Ikeda A, Fukuyama H, et al. Cortical myoclonus. Sensorimotor hyperexcitability. Neurology 1998b;50:933-42. 
Mima T, Hallett M. Corticomuscular coherence: A review. J Clin Neurophysiol 1999;16:501-11.

Molnar GF, Pilliar A, Lozano AM, Dostrovsky JO. Differences in neuronal firing rates in pallidal and cerebellar receiving areas of thalamus in patients with Parkinson's disease, essential tremor, and pain. J Neurophysiol 2005;93:3094-101.

Muente TF, Altenmuller E, Jancke L. The musician's brain as a model of neuroplasticity. Nat Rev Neurosci 2002;3:473-8.

Murase N, Kaji R, Shimazu H, Katayama-Hirota M, Ikeda A, Kohara N, et al. Abnormal premovement gating of somatosensory input in writer's cramp. Brain 2000;123:1813-29.

Nagamine T, Kajola M, Salmelin R, Shibasaki H, Hari R. Movement-related slow cortical magnetic fields and changes of spontaneous MEG-and EEG-brain rhythms. Electroenceph Clin Neurophysiol 1996;99:274-86.

Neshige R, Luders H, Shibasaki H. Recording of movement-related potentials from scalp and cortex in man. Brain 1988;111:719-36.

Noachtar S, Holthausen H, Luders HO. Epileptic negative myoclonus. Subdural EEG recordings indicate a postcentral generator. Neurology 1997;49:1534-7.

Obeso JA, Rothwell JC, Marsden CD. Simple tics in Gilles de la Tourette's syndrome are not prefaced by a normal premovement EEG potential. J Neurol Neurosurg Psychiatry 1981;44:735-8.

Oga T, Honda M, Toma K, Murase N, Okada T, Hanakawa T, et al. Abnormal cortical mechanism of voluntary muscle relaxation in patients with writer's cramp: an fMRI study. Brain 2002;125:895-903.

Ohara S, Ikeda A, Kunieda T, Yazawa S, Baba K, Nagamine T, et al. Movement-related change of electrocorticographic activity in human supplementary motor area proper. Brain. 2000a ;123:1203-15. 
Ohara S, Nagamine T, Ikeda A, Kunieda T, Matsumoto R, Taki W, et al.

Electrocorticogram-electromyogram coherence during isometric contraction of hand muscle in human. Clin Neurophysiol 2000b;111:2014-24.

Ohara S, Mima T, Baba K, Ikeda A, Kunieda T, Matsumoto R, et al. Increased synchronization of cortical oscillatory activities between human supplementary motor and primary sensorimotor areas during voluntary movements. J Neurosci 2001;21:9377-86.

Orgogozo JM, Larsen B. Activation of the supplementary motor area during voluntary movement in man suggests it works as a supramotor area. Science 1979;206:847-50.

Pfurtscheller G, Aranibar A. Event-related cortical desynchronization detected by power measurements of scalp EEG. Electroenceph Clin Neurophysiol 1977;42:817-26.

Pfurtscheller G, Neuper C. Movement and ERD/ERS. In: Jahanshahi M, Hallett M, editors. The Bereitschaftspotential. Movement-related cortical potentials. New York: Kluver Academic/Plenum Publishers; 2003. p. 191-206.

Pfurtscheller G. The cortical activation model (CAM). Prog Brain Res 2006;159:19-27.

Rao SM, Binder PA, Hammeke TA, Yetkin FZ, Jesmanowicz A, Lisk LM, et al. Functional magnetic resonance imaging of complex human movements. Neurology 1993;43:2311-8.

Ridding MC, Sheean G, Rothwell JC, Inzelberg R, Kujirai T. Changes in the balance between motor cortical excitation and inhibition in focal, task specific dystonia. $J$ Neurol Neurosurg Psychiatry 1995;59:493-8.

Rizzolatti G, Fabbri-Destro M. Mirror neurons: from discovery to autism. Exp Brain Res 2010;200:223-37.

Rizzolatti G, Sinigaglia C. The functional role of the parieto-frontal mirror circuit: interpretations and misinterpretations. Nat Rev Neurosci 2010;11:264-74.

Roland PE, Larsen B, Lassen NA, Skinhoj E. Supplementary motor area and other 
cortical areas in organization of voluntary movements in man. J Neurophysiol 1980;43:118-36.

Rubboli G, Mai R, Meletti S, Francione S, Cardinale F, Tassi L, et al. Negative myoclonus induced by cortical electrical stimulation in epileptic patients. Brain 2006;129:65-81.

Sadato N, Campbell G, Ibanez V, Deiber M, Hallett M. Complexity affects regional cerebral blood flow change during sequential finger movements. J Neurosci 1996;16:2691-700.

Salenius S, Portin K, Kajola M, Salmelin R, Hari R. Cortical control of human motoneuron firing during isometric contraction. J Neurophysiol 1997;77:3401-5.

Satow T, Ikeda A, Yamamoto J, Begum T, Thuy DH, Matsuhashi M, et al. Role of primary sensorimotor cortex and supplementary motor area in volitional swallowing: a movement-related cortical potential study. Amer J Physiol Gastrointest Liver Physiol 2004;287:G459-70.

Shibasaki H, Kuroiwa Y. Electroencephalographic correlates of myoclonus. Electroenceph Clin Neurophysiol 1975;39:455-63.

Shibasaki H, Shima F, Kuroiwa Y. Clinical studies of the movement-related cortical potential (MP) and the relationship between the dentatorubrothalamic pathway and readiness potential (RP). J Neurol 1978;219:15-25.

Shibasaki H, Barrett G, Halliday E, Halliday AM. Components of the movement-related cortical potential and their scalp topography. Electroenceph Clin Neurophysiol 1980a;49:213-26.

Shibasaki H, Barrett G, Halliday E, Halliday AM. Cortical potentials following voluntary and passive finger movements. Electroenceph Clin Neurophysiol 1980b;50:201-13.

Shibasaki H, Barrett G, Halliday E, Halliday AM. Cortical potentials associated with voluntary foot movement in man. Electroenceph Clin Neurophysiol 1981;52:507-16. 
Shibasaki H, Yamashita Y, Neshige R, Tobimatsu S, Fukui R. Pathogenesis of giant somatosensory evoked potentials in progressive myoclonic epilepsy. Brain 1985;108:225-40.

Shibasaki H, Barrett G, Neshige R, Hirata I, Tomoda H. Volitional movement is not preceded by cortical slow negativity in cerebellar dentate lesion in man. Brain Res $1986 ; 368: 361-5$.

Shibasaki H, Sadato N, Lyshkow H, Yonekura Y, Honda M, Nagamine T, et al. Both primary motor cortex and supplementary motor area play an important role in complex finger movement. Brain 1993;116:1387-98.

Shibasaki H, Ikeda A, Nagamine T, Mima T, Terada K, Nishitani N, et al. Cortical reflex negative myoclonus. Brain 1994;117:477-86.

Shibasaki H, Fukuyama H, Hanakawa T. Neural control mechanisms for normal versus Parkinsonian gait. Progr Brain Res 2004;143:199-205.

Shibasaki H, Hallett M. Electrophysiological studies of myoclonus. Muscle Nerve 2005;31:157-74.

Shibasaki H, Hallett M. What is the Bereitschaftspotential? Clin Neurophysiol 2006;117:2341-56.

Shibasaki H, Ikeda A, Nagamine T. Use of magnetoencephalography in the presurgical evaluation of epilepsy patients. Clin Neurophysiol 2007;118:1438-48.

Shibasaki H. Human brain mapping: Hemodynamic response and electrophysiology. Clin Neurophysiol 2008;119:731-43.

Simonetta M, Clanet M, Rascol O. Bereitschaftspotential in a simple movement or in a motor sequence starting with the same simple movement. Electroenceph Clin Neurophysiol 1991;81-129-34.

Sohn YH, Hallett M. Disturbed surround inhibition in focal hand dystonia. Ann Neurol 
2004;56:595-9.

Sudmeyer M, Pollok B, Hefter H, Gross J, Butz M, Wojtecki L, et al. Synchronized brain networks underlying postural tremor in Wilson's disease. Mov Disord 2006;21:1935-40.

Sutton GG, Mayer RF. Focal reflex myoclonus. J Neurol Neurosurg Psychiatry 1974;37:207-17.

Taniguchi S, Kimura J, Yanagisawa T, Okada F, Yamada T, Taniguchi S, et al. Rest-induced suppression of anterior horn cell excitability as measured by $\mathrm{F}$ waves: comparison between volitionally inactivated and control muscles. Muscle Nerve 2008;37:343-9.

Tatu L, Moulin T, Martin V, Monnier G, Rumbach L. Unilateral pure thalamic asterixis: Clinical, electromyographic, and topographic patterns. Neurology 2000;54:2339-42.

Tecchio F, Melgari JM, Zappasodi F, Porcaro C, Milazzo D, Casetta E, et al. Sensorimotor integration in focal task-specific hand dystonia: a magnetoencephalographic assessment. Neurosci 2008;154:563-71.

Terada K, Ikeda A, Nagamine T, Shibasaki H. Movement-related cortical potentials associated with voluntary muscle relaxation. Electroenceph Clin Neurophysiol 1995a;95:335-45.

Terada K, Ikeda A, Van Ness PC, Nagamine T, Kaji R, Kimura J, et al. Presence of Bereitschaftspotential preceding psychogenic myoclonus: clinical application of jerk-locked back averaging. J Neurol Neurosurg Psychiatry 1995b;58:745-7.

Terada K, Ikeda A, Yazawa S, Nagamine T, Shibasaki H. Movement-related cortical potentials associated with voluntary relaxation of foot muscles. Clin Neurophysiol 1999;110:397-403.

Timmermann L, Gross J, Dirks M, Volkmann J, Freund H-J, Schnitzler A. The cerebral oscillatory network of parkinsonian resting tremor. Brain 2003;126:199-212.

Toma K, Honda M, Hanakawa T, Okada T, Fukuyama H, Ikeda A, et al. Activities of the 
primary and supplementary motor areas increase in preparation and execution of voluntary muscle relaxation: an event-related fMRI study. J Neurosci 1999;19: 3527-34.

Toma K, Nagamine T, Yazawa S, Terada K, Ikeda A, Honda M, et al. Desynchronization and synchronization of central $20-\mathrm{Hz}$ rhythms associated with voluntary muscle relaxation: a magnetoencephalographic study. Exp Brain Res 2000;134:417-25.

Uesaka Y, Ugawa Y, Yumoto M, Sakuta M, Kanazawa I. Giant somatosensory evoked magnetic field in patients with myoclonus epilepsy. Electroenceph Clin Neurophysiol 1993;87:300-5.

Uesaka Y, Terao Y, Ugawa Y, Yumoto M, Hanajima R, Kanazawa I.

Magnetoencephalographic analysis of cortical myoclonic jerks. Electroenceph Clin Neurophysiol 1996;99:141-8.

Upton ARM, McComas AJ, Sica REP. Potentiation of 'late' responses evoked in muscles during effort. J Neurol Neurosurg Psychiatry 1971;34:699-711.

van Rootselaar AF, Aronica E, Jansen Steur EN, Rozemuller-Kwakkel JM, de Vos RA, Tijssen MA. Familial cortical tremor with epilepsy and cerebellar pathological findings. Mov Disord 2004;19:213-7.

van Rootselaar AF, van der Salm SMA, Bour LJ, Edwards MJ, Brown P, Aronica E. et al. Decreased cortical inhibition and yet cerebellar pathology in 'familial cortical myoclonic tremor with epilepsy'. Mov Disord 2007;22:2378-85.

Vidailhet M, Stocchi F, Rothwell JC, Thompson PD, Day BL, Brooks DJ, et al. The Bereitschaftspotential preceding simple foot movement and initiation of gait in Parkinson's disease. Neurology 1993;43:1784-8.

Wang S, Aziz TZ, Stein JF, Bain PG, Liu X. Physiological and harmonic components in neural and muscular coherence in Parkinsonian tremor. Clin Neurophysiol 2006;117:1487-98. 
Wheaton LA, Shibasaki H, Hallett M. Temporal activation pattern of parietal and premotor areas related to praxis movements. Clin Neurophysiol 2005a;116:1201-12.

Wheaton LA, Nolte G, Bohlhalter S, Fridman E, Hallett M. Synchronization of parietal and premotor areas during preparation and execution of praxis hand movements. Clin Neurophysiol 2005b;116:1382-90.

Yamamoto J, Ikeda A, Satow T, Matsuhashi M, Baba K, Yamane F, et al. Human eye fields in the frontal lobe as studied by epicortical recording of movement-related cortical potentials. Brain 2004;127:873-87.

Yazawa S, Shibasaki H, Ikeda A, Terada K, Nagamine T, Honda M. Cortical mechanism underlying externally cued gait initiation studied by contingent negative variation. Electroenceph Clin Neurophysiol $1997 ; 105: 390-9$.

Yazawa S, Ikeda A, Kunieda T, Mima T, Nagamine T, Ohara S, et al. Human supplementary motor area is active in preparation for both voluntary muscle relaxation and contraction: subdural recording of Bereitschaftspotential. Neurosci Lett 1998;244:145-8.

Yazawa S, Ikeda A, Kaji R, Terada K, Nagamine T, Kubori T, et al. Abnormal cortical processing of voluntary muscle relaxation in patients with focal hand dystonia as studied by movement-related potentials. Brain 1999;122:1357-66.

Yazawa S, Ikeda A, Kunieda T, Ohara S, Mima T, Nagamine T, et al. Human pre-supplementary motor area is active before voluntary movement: subdural recording of Bereitschaftspotential from medial frontal cortex. Exp Brain Res 2000;131:165-77.

Zoons E, Booij J, Nederveen AJ, Dijk JM, Tijssen MAJ. Structural, functional and molecular imaging of the brain in primary focal dystonia - A review. NeuroImage 2011;56:1011-20. 


\section{Legends for Figures}

Figure 1

Brain areas more activated in the judgment of graspable objects than in that of non-graspable objects based on event-related fMRI study (a) and results of psychophysiological interaction analysis (b). In the fMRI data (a), two clusters in the left inferior parietal lobule (IPL) and a cluster in the left premotor area (PMA) were found to be significantly more activated in the judgment of graspable objects as compared with that of non-graspable objects. At the bottom, the parameter estimates of the two parietal clusters are shown for graspable objects (Graspable) and non-graspable objects (No). In psychophysiological interaction (b), the left dorsal IPL had functional connectivity to the left ventral PMA, SMA and right cerebellar cortex (shown in green), whereas the left ventral IPL had functional connectivity to the left dorsolateral prefrontal cortex and pre-SMA (shown in red). (Cited from Hattori et al., 2009 with permission)

\section{Figure 2}

Cortical activation in motor imagination and actual motor execution studied by BP (a) and functional MRI (b). In (a), BPs recorded from the midline vertex electrode $(\mathrm{Cz})$ in association with finger (top) and shoulder movement (bottom) are shown comparing self-paced (black), cued (blue) and imagined (red) conditions. Note a slowly rising negative potential (early BP) in all three conditions throughout the pre-movement period both in finger and shoulder movements (shown in red). Late BP is clearly seen in self-initiated and cued movements, which is larger with the shoulder movement than with the finger movement most likely because the shoulder area of M1 and that of the lateral PMA are closer to Cz compared with the corresponding finger areas. In an event-related functional MRI study employing finger movement (b), activation in SMA is nearly the same between the motor execution and the imagination whereas in M1 it is conspicuous in the motor execution but nearly absent in the imagination. ((a) cited from Jankelowitz and Colebatch, 2002 and (b) cited from Cunnington et al., 2005 with permission)

\section{Figure 3}

Timing of conscious intention to move relative to BP studied by a new 
method by Matsuhashi and Hallett (2008). In their paradigm (a), subjects were instructed to repeat finger movement at a self-paced rate of once every $5-10 \mathrm{~s}$ while tones were applied pseudo-randomly at intervals of $3-20 \mathrm{~s}$, and they were instructed to stop the movement if they heard the tone after they started thinking about the movement ('Veto'). If the tone was presented too close to the movement onset, the movement can no longer be vetoed ('No return'). If the tone was heard while they were not thinking about the next movement, they just ignored the tone ('Ignore'). Solid triangles at the bottom indicate increasing intention to move. In the result (b), the estimated time of the occurrence of intention to move $(\mathrm{T})$, point of no return (P), onset of early BP (BP1), onset of late BP (BP2), and reaction time (RT) are shown with respect to the EMG onset. T was $1.42 \mathrm{~s}$ on average before the movement onset. (Modified (a) and cited (b) from Matsuhashi and Hallett, 2008 with permission)

Fig. 4

EEGs associated with psychogenic jerks of trunk and self-initiated movements mimicking the jerks, arranged time-locked to the EMG discharge. Fifty traces of individual EEG records are shown on the top panel (Single trial) and averaged waveforms are shown on the bottom (Averaged). In single trials, blue and red colors indicate surface-negative and surface-positive, respectively. Note slowly rising surface-negative potential preceding both the psychogenic jerks and the mimicking jerks. (By courtesy of Dr. Zoltan Mari currently at Johns Hopkins Hospital)

Fig. 5

SEPs recorded from scalp (CPz) and subdural electrodes (S1 and M1) to electrical stimulation of the left tibial nerve in a patient with focal cortical reflex myoclonus involving the left foot. Two sub-averages are overlaid. The first response is seen at the $\mathrm{S} 1$ foot area with the latency of the negative peak $59.5 \mathrm{~ms}$, and $5.3 \mathrm{~ms}$ later it is followed by the response at the M1 foot area. At the scalp electrode, it is seen as a single response with the latency nearly the same as that of the M1 response. (Cited from Hitomi et al., 2006 with permission)

Fig. 6 
Reduced short-interval intracortical inhibition in patients with sialidosis type I presenting with cortical myoclonus. Based on paired pulse TMS study. (cited from Huang et al., 2008 with permission)

Fig. 7

EEG-EMG coherence in a 78-year-old patient with hereditary essential tremor who developed Parkinson's disease 50 years after the clinical onset of essential tremor. EEG was recorded from the right fronto-central region (FC4-C4) and the surface EMG was recorded from the left forearm. The peak frequency of resting tremor was $4.3 \mathrm{~Hz}$ and that of postural (essential) tremor was $5.2 \mathrm{~Hz}$. There was a significant cortico-muscular coherence for postural tremor as well as resting tremor at each tremor frequency.

(Modified from Inoue et al., 2007 with permission) 
Fig. 1a

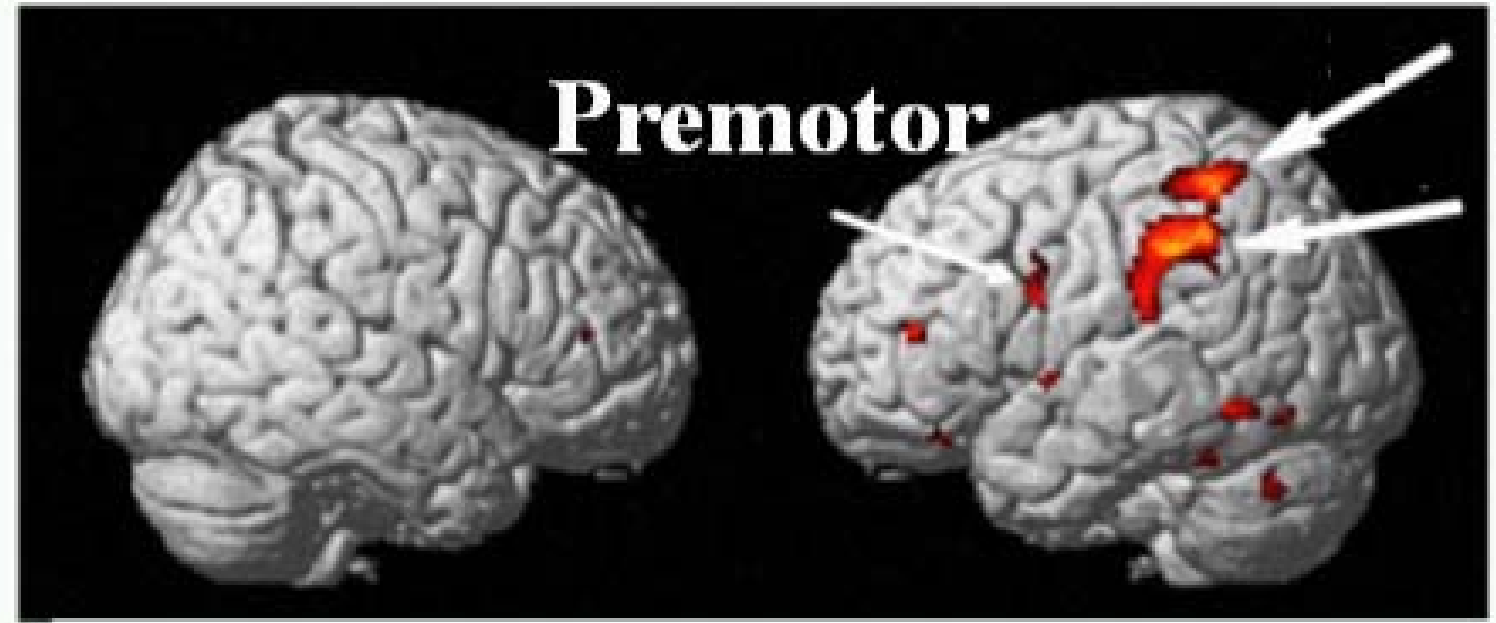

\section{Dorsal IPL \\ Ventral IPL}

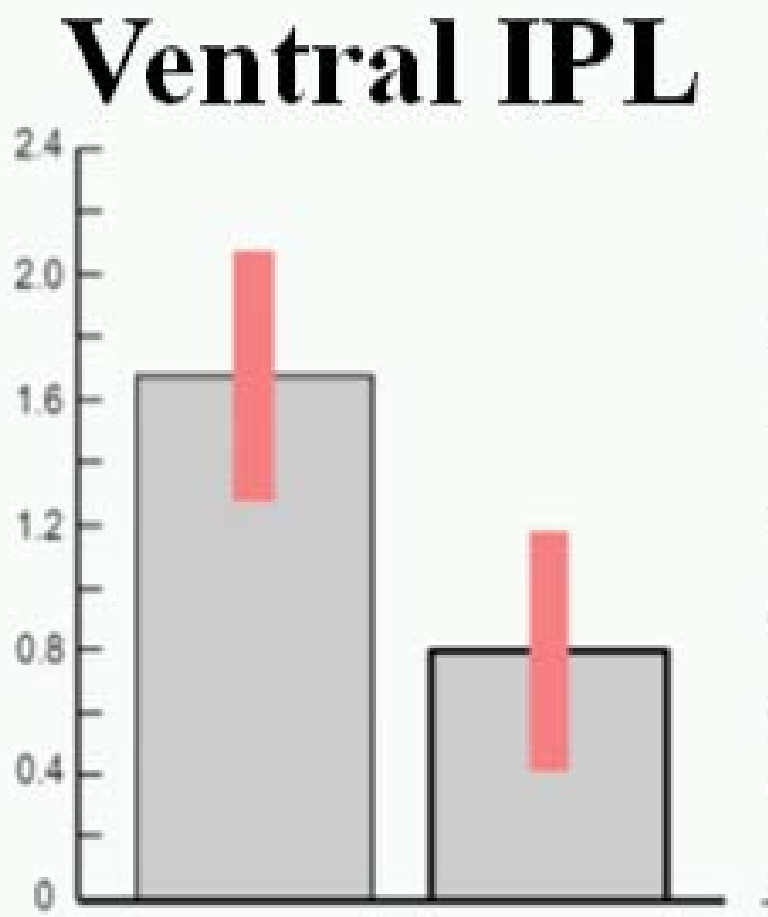

Graspable No

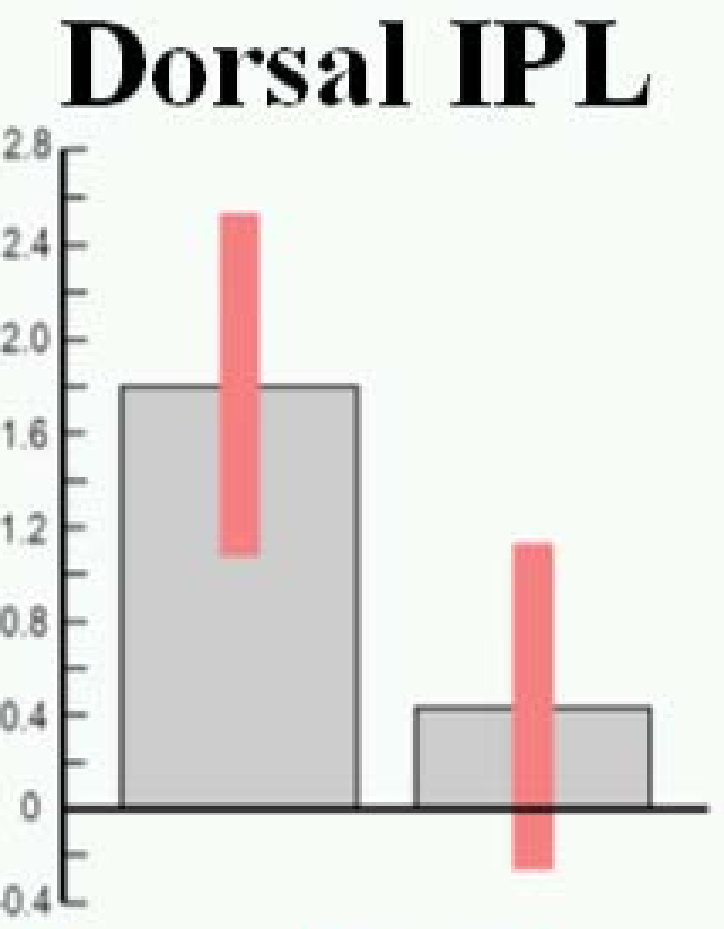

Graspable No 
Fig. $1 \mathrm{~b}$

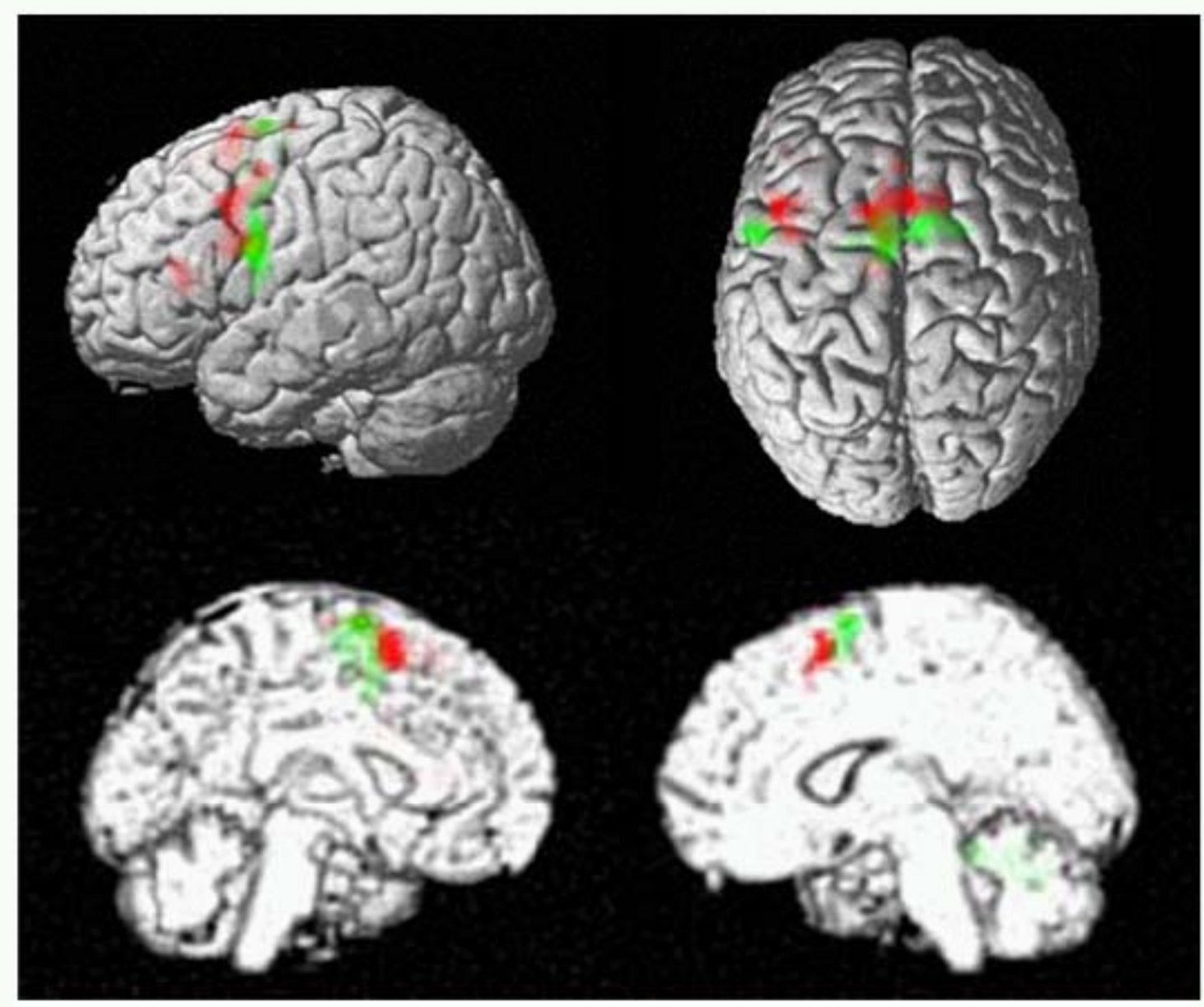



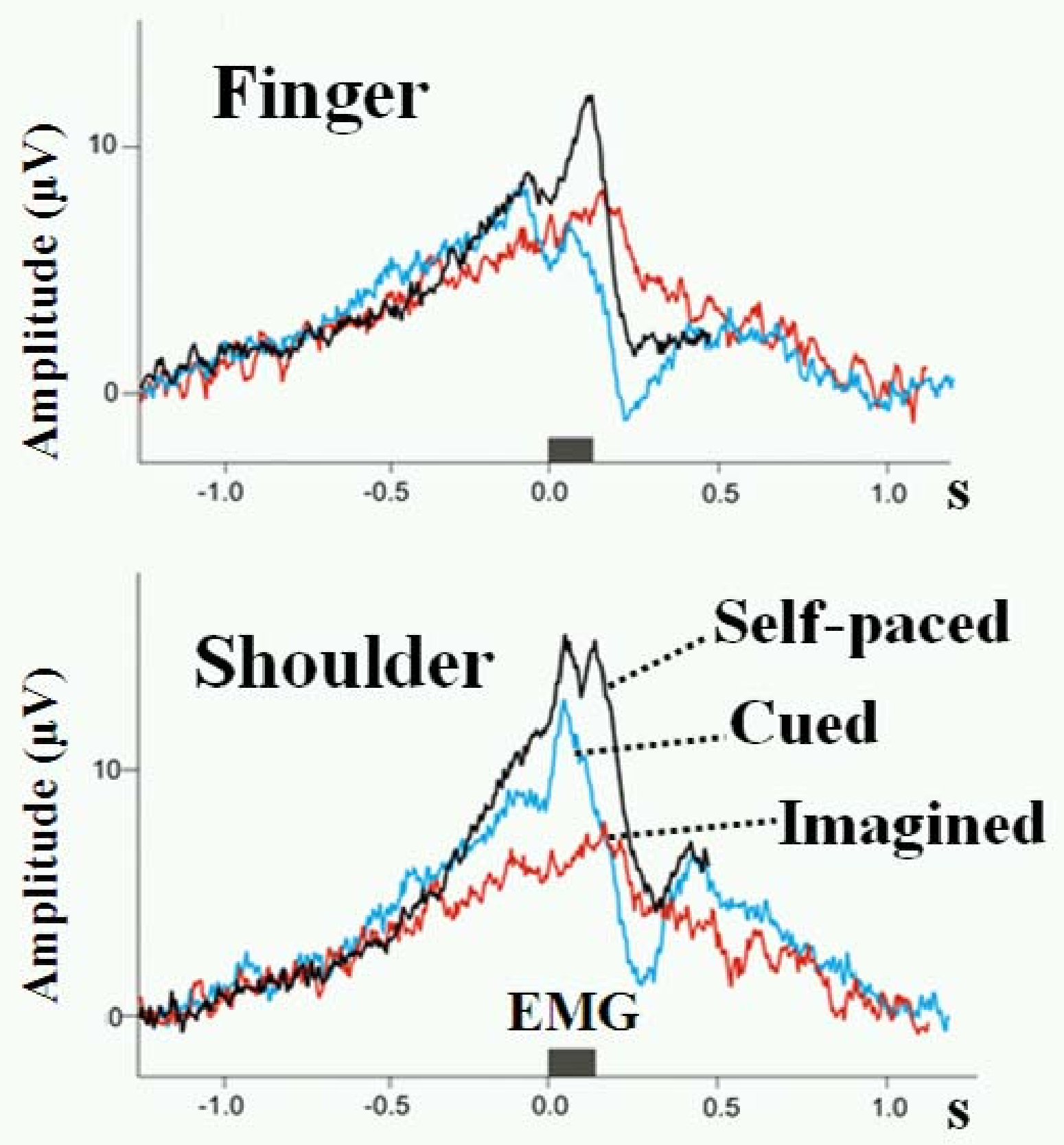

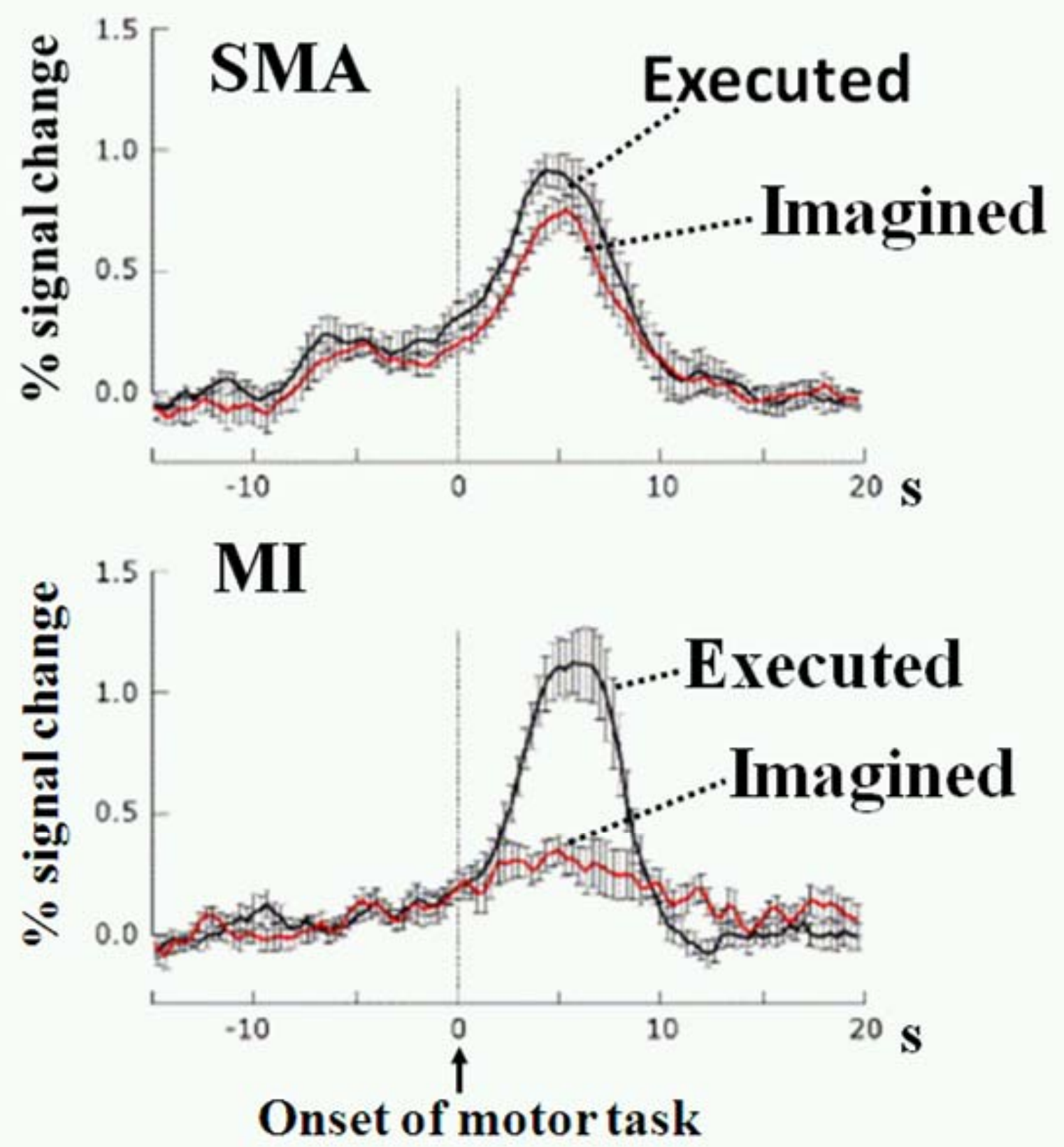
Fig. 3a

'Ignore' 'No return' 'Veto'

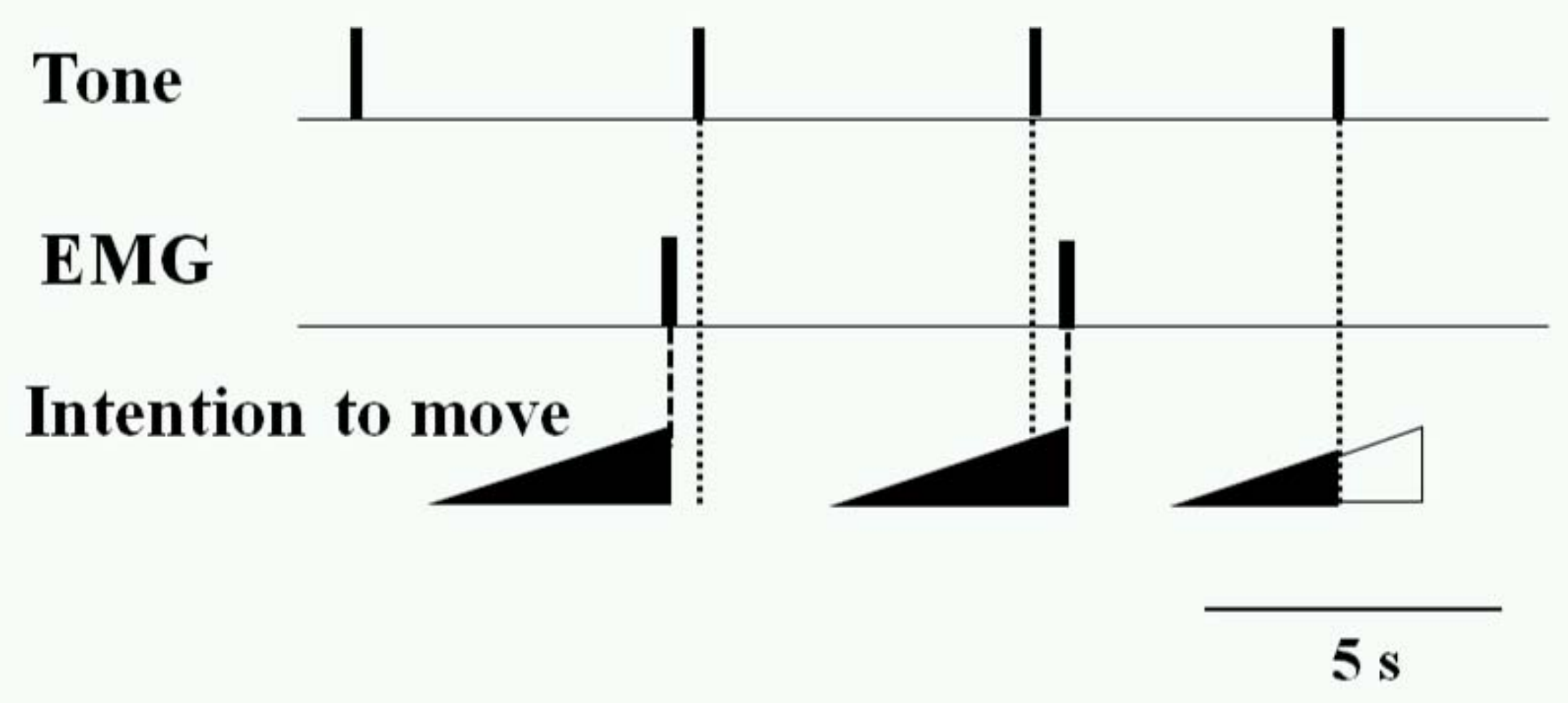


Fig. 3b

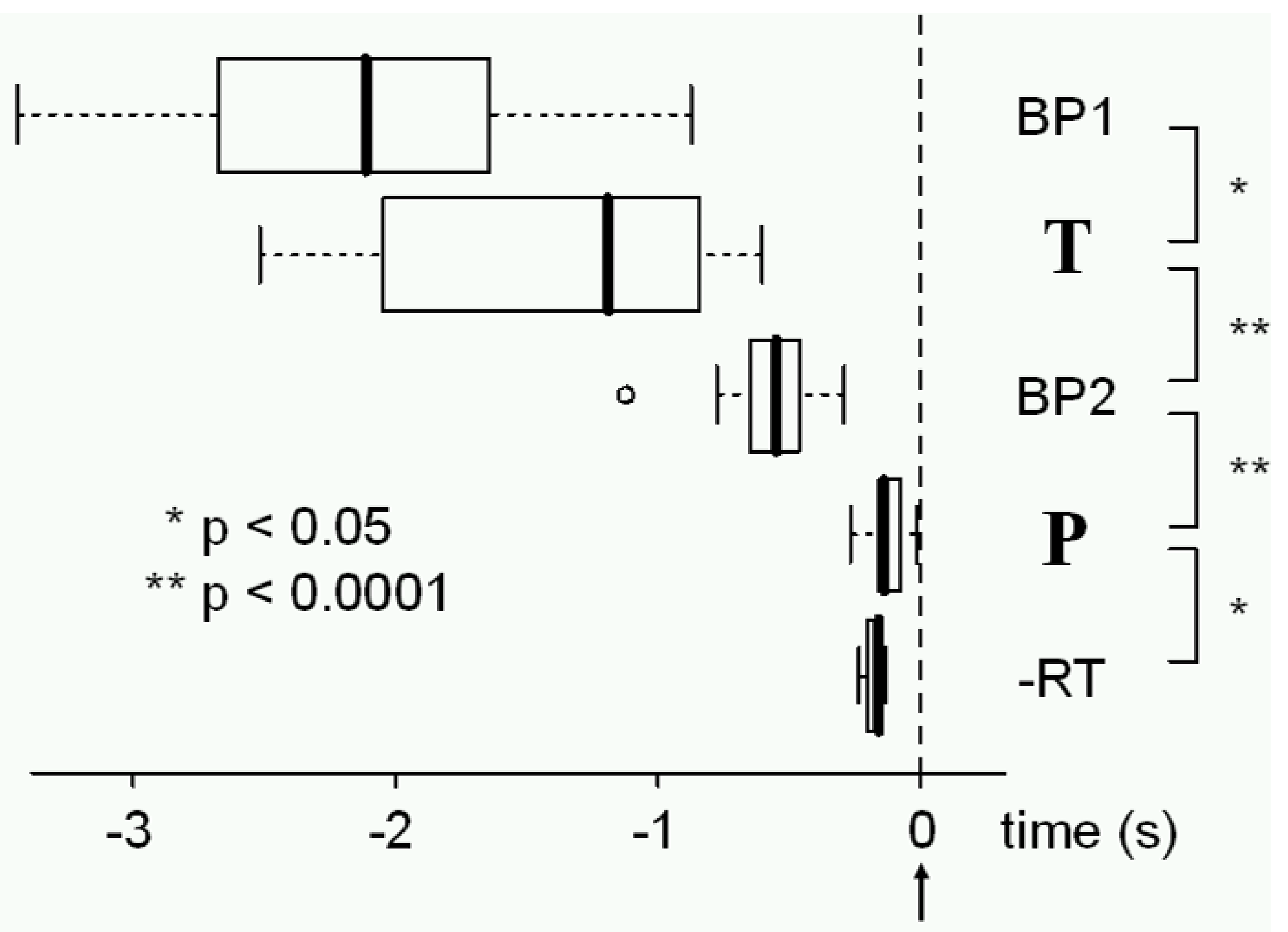

EMG onset 
Fig. 4

\section{Psychogenic Jerks}

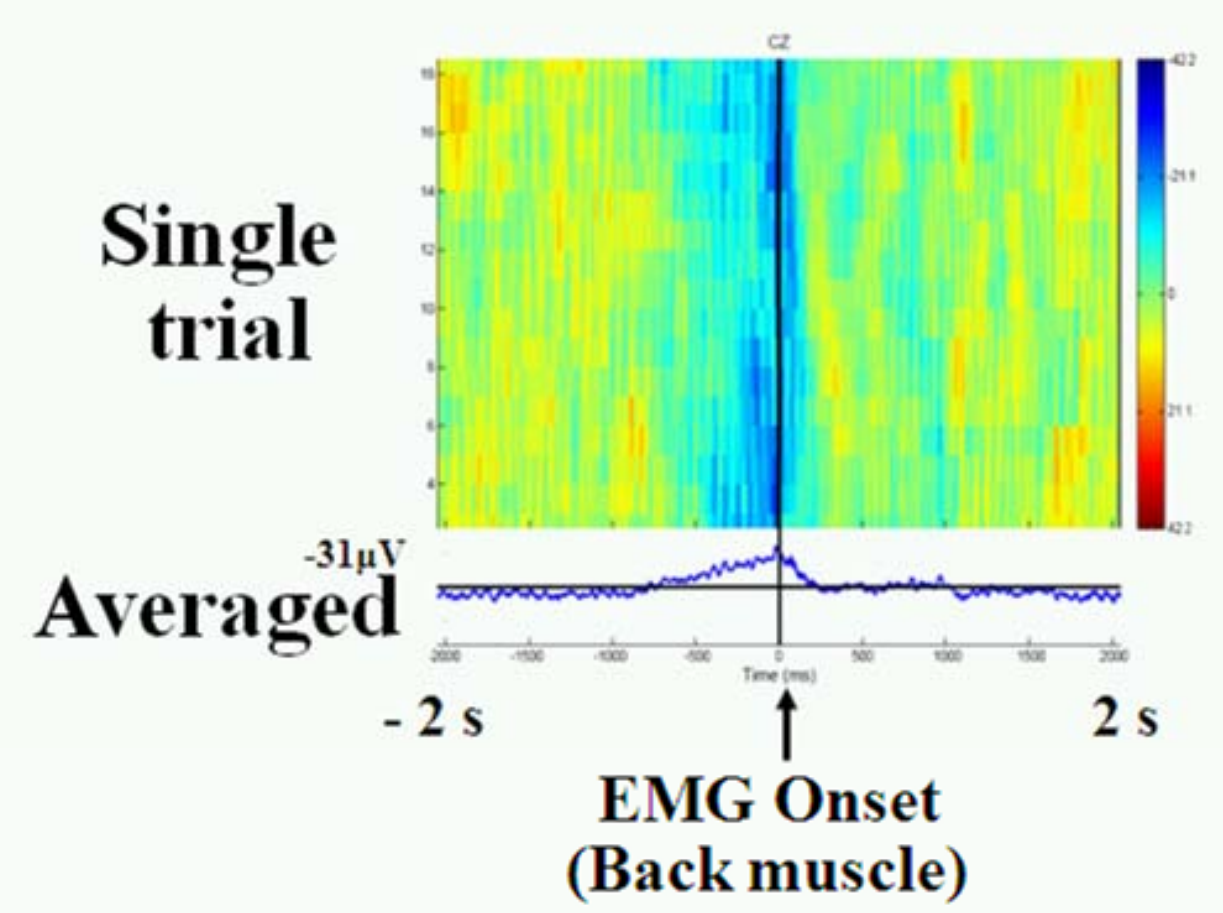

\section{Mimicking Movement}

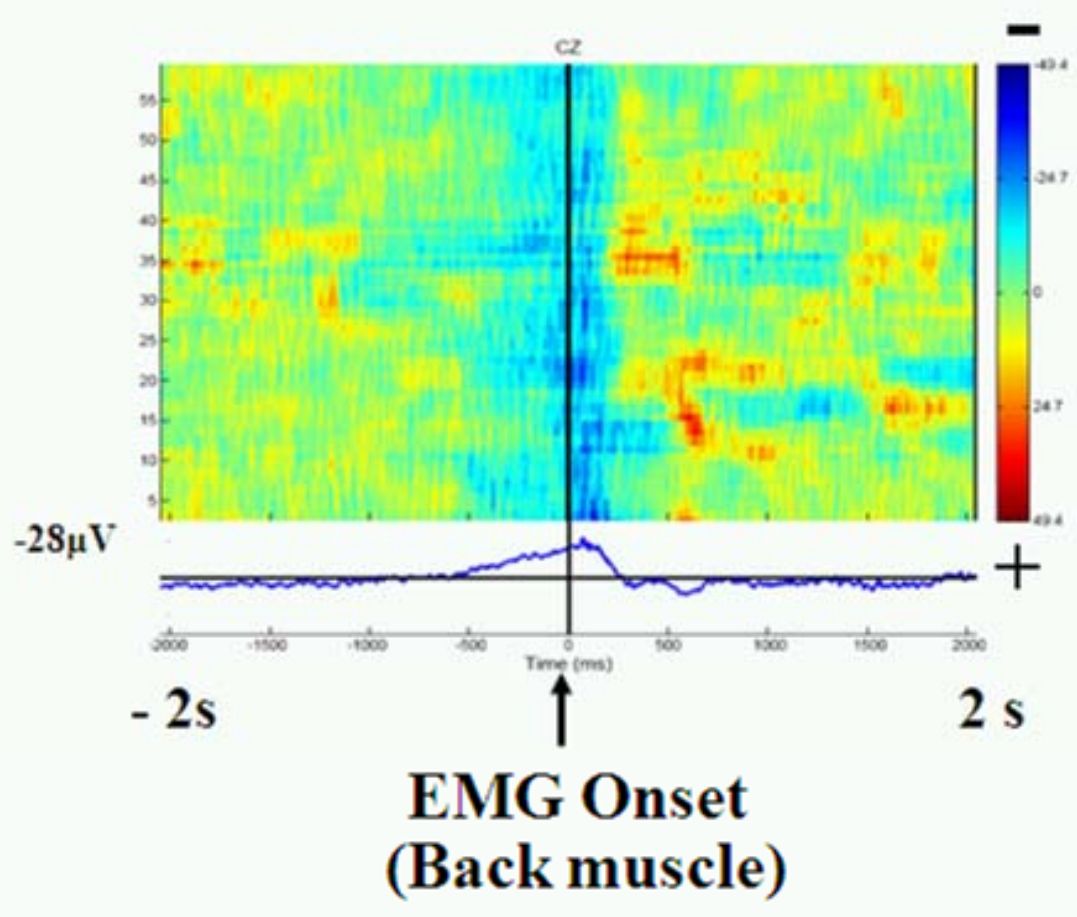


Fig. 5

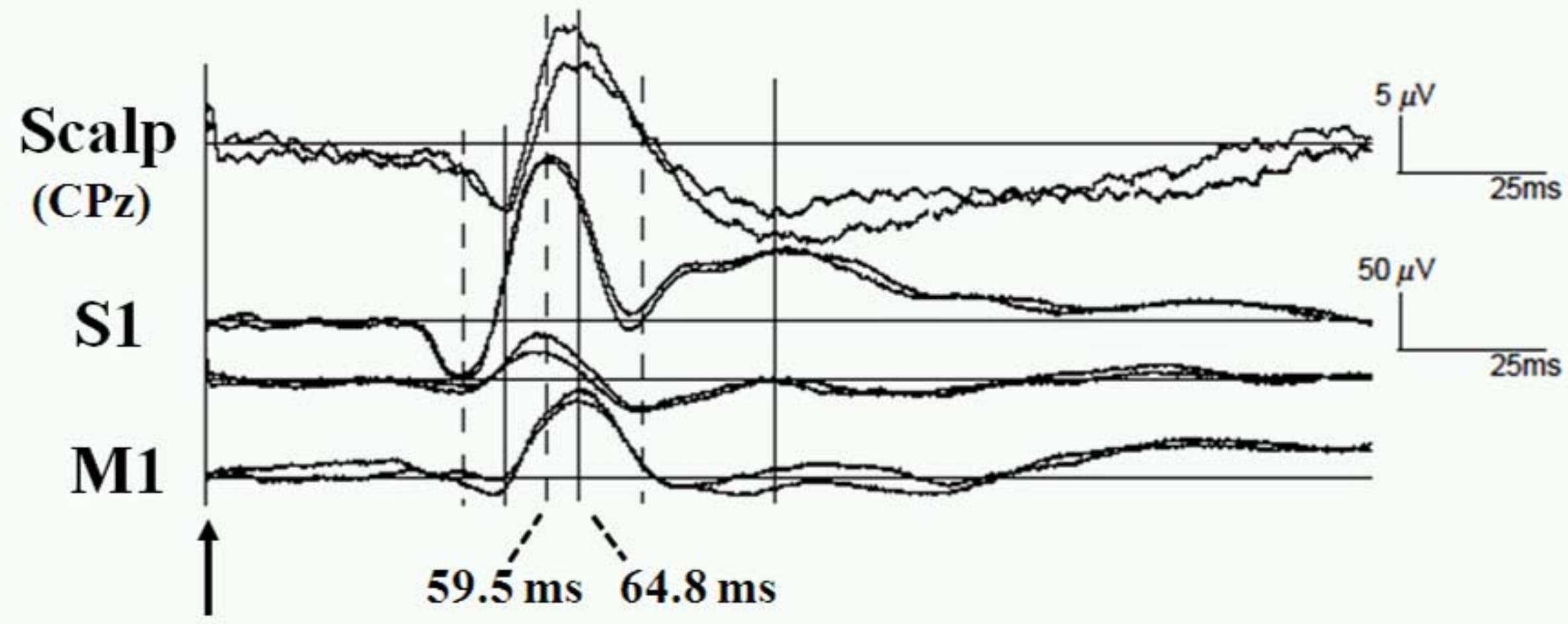

L tibial n. stim. 
Fig. 6

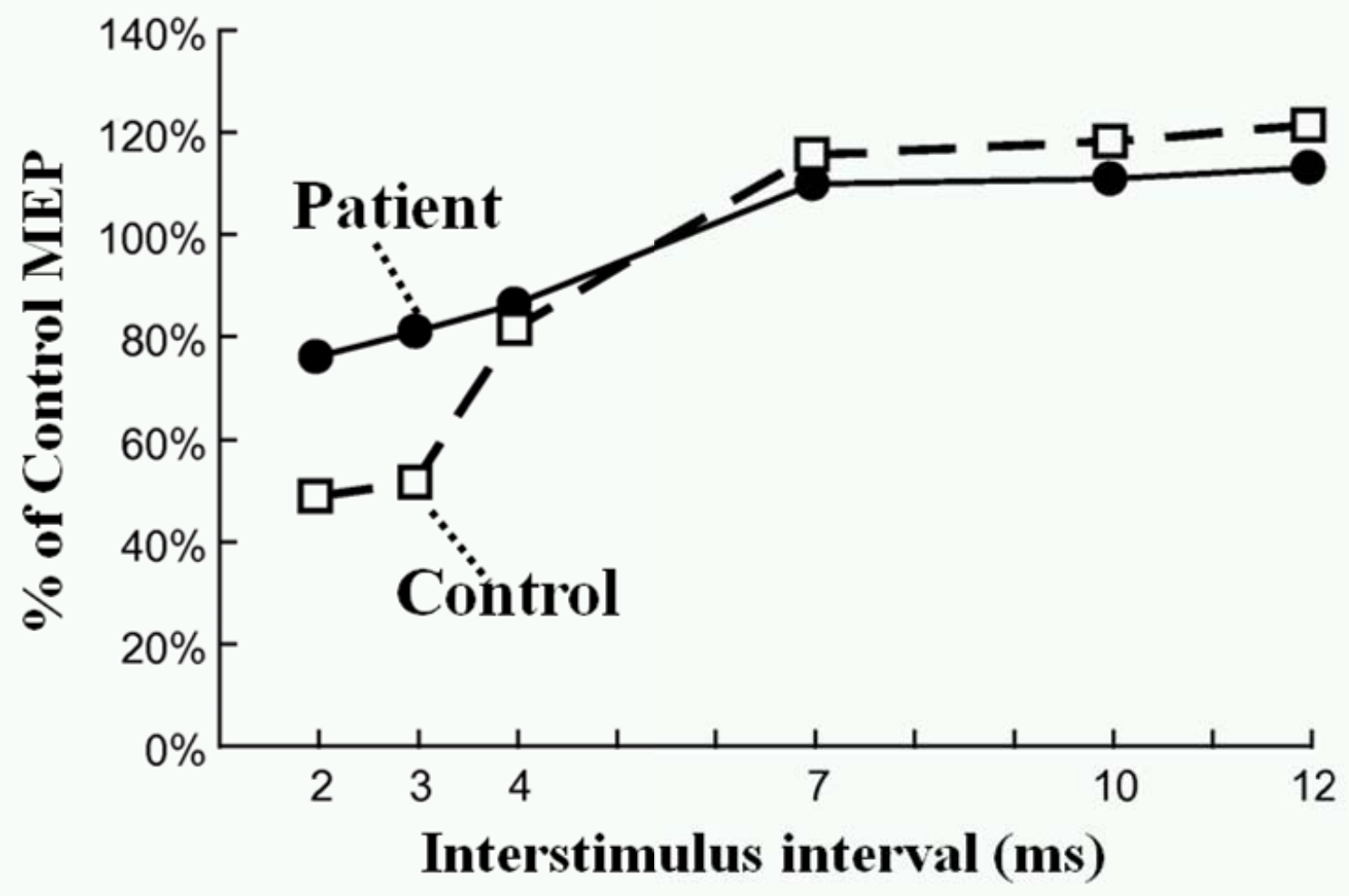


Fig. 7

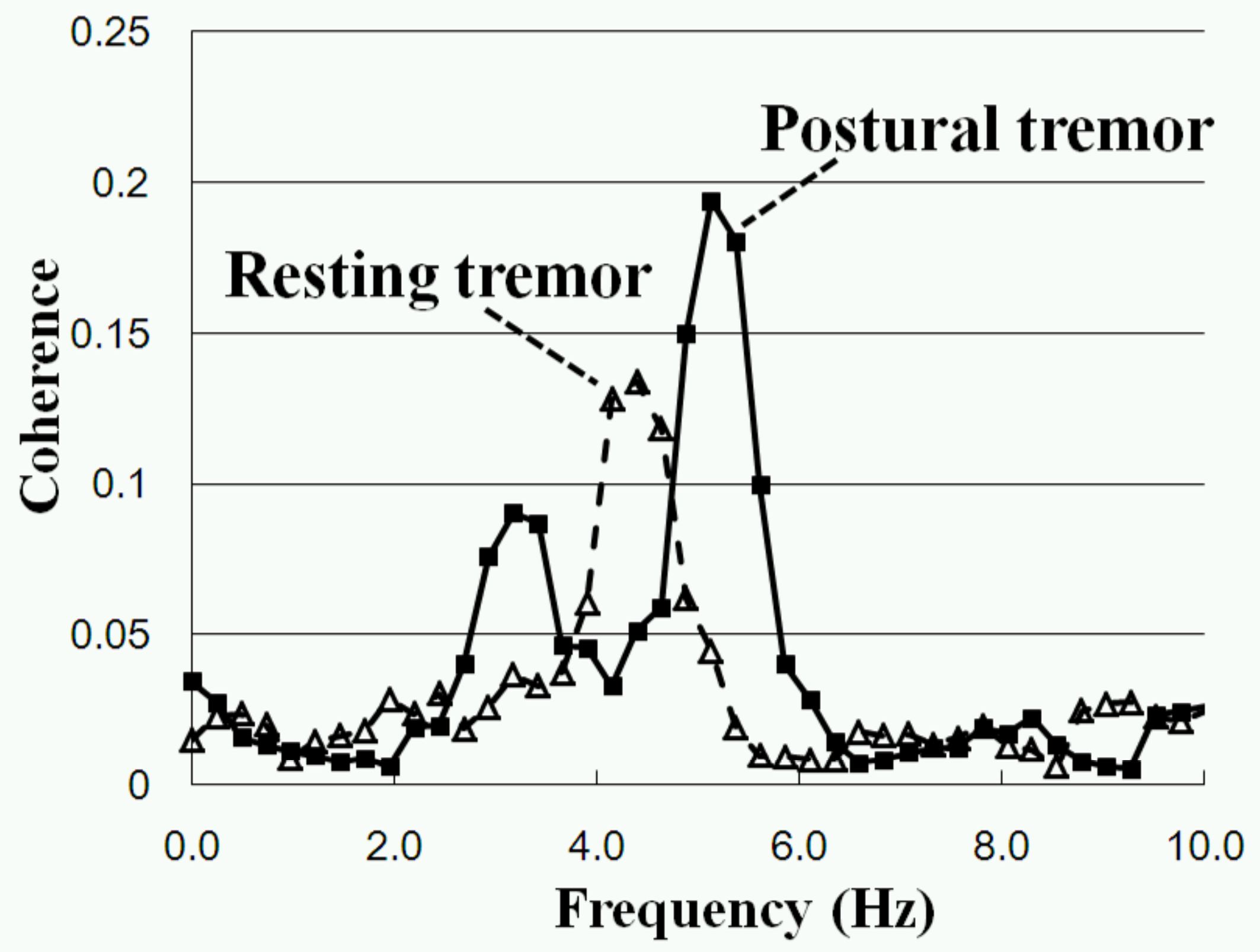

